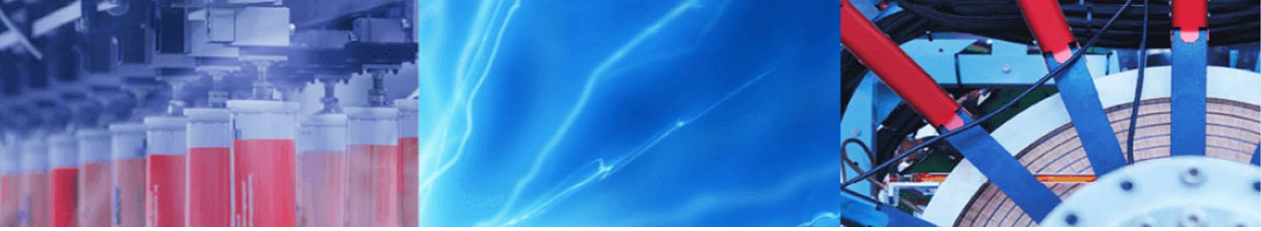

Research Article

\title{
Green synthesis and anticorrosion effect of Allium cepa peels extract-silver nanoparticles composite in simulated oilfield pickling solution
}

\author{
Ekemini Ituen ${ }^{1,2,3} \cdot$ Ambrish Singh $^{1,2} \cdot$ Lin Yuanhua $^{1,2} \cdot$ Onyewuchi Akaranta ${ }^{4}$
}

Received: 16 April 2020 / Accepted: 19 May 2021

Published online: 31 May 2021

(C) The Author(s) 2021 OPEN

\begin{abstract}
An alternative green approach through which nanoscience/nanotechnology could be applied in the industry is being demonstrated in this study. Ethanol extracts of Allium cepa peels (Et-ACPE) is used to mediate the synthesis of silver nanoparticles (Et-AgNPs) at room temperature. Stable crystalline, monodisperse and non-agglomerated spherical NPs with zeta potential of $-46.2 \pm 0.1 \mathrm{mV}$ and plasmon absorption at $435 \mathrm{~nm}$ are obtained. Silver atoms are predominantly oriented towards the $\mathrm{Ag}(111)$ plane in a face centered cubic structure with $a=b=c=4.0968 \AA$ having $\alpha=\beta=\gamma=90^{\circ}$. The surfaces of the NPs becomes rich in electron cloud due to $O$ atoms supplied by capped phyto-compounds of EtACPE. This enhances adsorption potential and more efficient inhibition (up to $90 \%$ at $30^{\circ} \mathrm{C}$ ) of $\mathrm{X} 80$ steel corrosion in $1 \mathrm{M}$ $\mathrm{HCl}$ solution than using the crude extract. Investigation of corrosion products and morphologies of the steel surface by FTIR, SEM/EDS and AFM techniques reveals efficient surface protection through adsorption of Et-AgNPs facilitated mainly by $\mathrm{O}$ and $-\mathrm{C}=\mathrm{C}-$ sites. Findings prove that the Et-AgNPs is a more efficient and thermally stable alternative ecofriendly anticorrosion additive for industrial cleaning and pickling operations than the crude extract.
\end{abstract}

Keywords Anticorrosion · Nanoparticles · Oilfield chemical · XRD · TEM · SEM/EDS

\section{Introduction}

Hydrochloric acid $(\mathrm{HCl})$ is an important inorganic acid that has been extensively used as industrial cleaning solution. Also called muriatic acid, it is used for cleaning surfaces of various metals and alloys, including steel, especially to remove scales, rust and mineral deposits. In general, $\mathrm{HCl}$ used is for chemical cleaning/pickling of steel, reduction of ores and processing, industrial preparation of chlorine and chlorides, acid treatment of oil and gas wells and in food processing [1]. However, $\mathrm{HCl}$ is known for its high corrosivity, and depending on temperature under which operation is carried out and the concentration of the acid used, it can rather be aggressive to and corrode the surfaces meant to be cleaned. To ameliorate the corrosive damage, materials selection has been the practice by many industries, but there is limited choice for potential corrosion resistant materials in $\mathrm{HCl}$. This is because on continuous contact of

\footnotetext{
Supplementary information The online version contains supplementary material available at https://doi.org/10.1007/s42452-021-04670w.

$\triangle$ Ekemini Ituen, ebituen@gmail.com; $\triangle$ Lin Yuanhua, yhlin28@163.com | 'State Key Laboratory of Oil and Gas Reservoir Geology and Exploitation, Southwest Petroleum University, Chengdu 610500, Sichuan, China. ${ }^{2}$ School of Materials Science and Engineering, Southwest Petroleum University, Chengdu 610500, Sichuan, China. ${ }^{3}$ Emerging Materials and Energy Research Group, Department of Chemistry, University of Uyo, Uyo, Nigeria. ${ }^{4}$ African Center of Excellence in Oilfield Chemicals Research, Institute of Petroleum Studies, University of Port Harcourt, Port Harcourt, Nigeria.
}

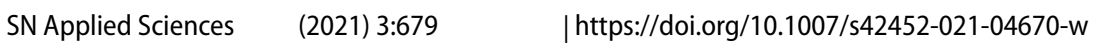


the material with $\mathrm{HCl}$, localized and/or general corrosion will still occur which may eventually result in failure of the material. Therefore, corrosion inhibitors need to be formulated into the acid to reduce $\mathrm{HCl}$ corrosive attack [2].

Added in very small quantities, corrosion inhibitors (Cls) act by adsorbing on the substrate surface and forming a surface protective thin film [3]. To select $\mathrm{Cl}$ for a given operation, cost effectiveness, low toxicity and environmental friendliness, efficiency at small concentrations, stability to varying operational temperatures and shelf life are some crucial factors to be considered $[4,5]$. Bearing these factors in mind, green Cls sourced from plant extracts often afford combined advantage over many organic Cls. Nevertheless, plant extracts are not resistant to degradation by heat or biochemical agents, hence their application is limited to low temperature operations. Also, if stored for long time, the efficiency of plant extracts often decline [5].

In recent researches, attention has been paid to how plant extracts may be modified to improve stability at high temperatures and resistance to bio-degradation. Extracts have been mixed with some additives such as potassium iodide [6-8], acetylacetonate [9], cerium nitrate [10], zinc oxide and zinc salt [11-13], sulphate ions [14] and praseodymium nitrate [15]. These additives enhanced the performance of plant extracts by synergistic effects [5]. Reaction between some active chemical compounds in plant extracts with metal salts may result in formation of metal ions complexes and/or nanoparticles (NPs) at appropriate biomass (extract) concentration, temperature and $\mathrm{pH}$. In the previously listed reports [6-14] where metal salts were used to synergistically intensify the efficiency of the Cls, nothing was done to confirm if the obtained product was in nano scale despite that materials are more reactive at nanoscale.

Synthesis of plant extracts nanoparticles often involve a single step bio-reduction reaction that occurs within short time even at room temperature [16]. Though NPs can be prepared by various routes, bio-synthetic pathway affords the advantage of obtaining the inexpensive, non-toxic and eco-environmental NPs in large quantities. Owing to their vast antimicrobial activities, bio-fabricated NPs have been applied in agriculture, medicine and pharmaceuticals [17]. In comparison to other metal ions, silver nanoparticles (AgNPs) are the most extensively reported. AgNPs have been established to exhibit antiprotozoal, antibacterial, antifungal and anticancer activities [17-21]. This has been attributed to slightly toxic nature of silver ions to the target. Silver ions reduce their growth/multiplication by tampering with their cell membrane $[16,18]$. Although many plant extracts have been demonstrated to efficiently inhibit corrosion, evaluating plant extract mediated NPs as Cls has received only little attention. In this study, we explore future research horizon in corrosion protection using plant extract mediated nanoparticles (PEMN) especially considering that there is a wide variety of plant materials which could be investigated.

From available literature, PEMN with anticorrosion activity was recently reports by Essien and co-workers [19] and Idrees and co-workers [20]. They used olive leaves [19] and Sida acuta [20] extracts as feedstock for fabrication of titanium and silver nanoparticles composites, respectively. For the Sida acuta mediated AgNPs potentiodynamic polarization method only was used to monitor corrosion progress in $0.5 \mathrm{M} \mathrm{H}_{2} \mathrm{SO}_{4}$ for 30 min while the biocide activity was more emphasized. Titanium NPs from olive leaves extract were to be used as adsorbents for scavenging heavy metal ions from waste water. In the process of studying the material, the authors also evaluated its anticorrosion effect. Since the obtained efficiency in $\mathrm{HCl}$ for steel was encouraging, it motivated us to evaluate extracts of some agro-wastes to develop more efficient biogenic NPs as alternative Cls for oilfield pickling. Agro-wastes are inexpensive and can be sustainably sourced locally as long as food is continually being consumed. Again, utilization of agro-wastes for corrosion protection eliminates competition of feedstock with food, could reduce environmental pollution while creating wealth from wastes.

In our previous (recent) reports, we have demonstrated that some PEMN using $\mathrm{Cu}, \mathrm{Ni}$ and $\mathrm{Ag}$ ions mediated exhibit better inhibition potential than previously reported NPs $[18,21,22]$. By using silver ions as capping agent and Allium cepa peels extract (ACPE) as catalyst, the present study also aims to achieve improved efficiency. Allium cepa (red onion) peels is can be domestically obtained without the need to buy. ACPE has been to contain more compounds than the inner shells $[23,24]$ and on observing the molecular structures of some of these compounds (Fig. 1) potential adsorption sites similar to those in reported organic corrosion inhibitors can be seen [25]. The availability of potential adsorption sites such as $\mathrm{O}-\mathrm{H}$, $\mathrm{C}-\mathrm{O}-\mathrm{C},-\mathrm{COO}-$ shown in Fig. 1 motivated the choice of ACPE as a feedstock for synthesis of the nanoscale corrosion inhibitor. Already, it is established that peels extract of red onions can inhibit steel corrosion in some aggressive solutions [26-28]. The present study therefore builds on these foundation reports and in addition provides/documents further insights on the optical/crystalline properties, adsorption behaviour and corrosion inhibition effects of PEMN.

\section{Experimental}

\subsection{Preparation of A. cepa peels extract (ACPE)}

Allium cepa peels (ACP) were obtained from sellers of onions at a nearby market to our university. The peels 
Fig. 1 Some major chemical compounds in Allium cepa extracts, namely (i) quercetin (ii) kaempferol (iii) ferulic acid and (iv) gallic acid<smiles>O=c1c(O)c(-c2ccc(O)c(O)c2)oc2cc(O)cc(O)c12</smiles><smiles></smiles>

(i)<smiles>C#CC=Cc1ccc(O)c(OC)c1</smiles>

(ii)<smiles>O=C(O)c1cc(O)c(O)c(O)c1</smiles>

were washed convincingly using de-ionized water, dried by spreading in the laboratory at room temperature [5]. The dry peels were ground to powdered and $100 \mathrm{~g}$ of the powder was soaked in $10,000 \mathrm{~mL}$ absolute ethanol at room temperature. Filtrate was concentrated and dried to powder at $35^{\circ} \mathrm{C}$ while the air-dried residue was weighed to evaluate extract yield. The extract was labelled Et-ACPE and stored in laboratory cupboard at room temperature for future use.

\subsection{Characterization of extract}

The elemental composition on the surface of the extract was determined by energy dispersive $\mathrm{X}$-ray spectroscopy (EDS). Absorbance and wavelengths of absorption were measured by UV-Visible spectroscopy within $400-800 \mathrm{~nm}$ range. The active functional groups in the extract was also characterized by FTIR.

\subsection{Preparation of silver nanoparticles}

The extract was initially prepared into 1000 ppm concentration. $500 \mathrm{~mL}$ of $1000 \mathrm{ppm}$ Et-CPE was mixed with $1000 \mathrm{~mL}$ of $1 \mathrm{mM} \mathrm{AgNO}$ at $25-30{ }^{\circ} \mathrm{C}$, stirred regularly and observed for firm colour change which indicates complete bio-reduction and formation of nanoparticles (NPs). The nanoparticles obtained was designated as EtAgNPs. Aliquot of the NPs was washed three times in distilled water, dried in oven at $35^{\circ} \mathrm{C}$ and used for further analyses while the remaining colloidal solution was stored in amber coloured reagent bottle inside laboratory cupboards at room temperature.

\subsection{Characterization of NPs}

Formation of plasmon was investigated by UV-Vis spectroscopy. Colloidal properties of the NPs were analysed by DLS in comparison with the crude extracts. X-ray diffraction (XRD) spectroscopy was used to investigate the crystallographic properties of the NPs at $2 \theta=10^{\circ}-90^{\circ}$, also in comparison with the extract. The morphology and size of the NPs was characterized by SEM and TEM. EDS was used to probe and compare the elemental composition of both the extract and NPs. FTIR spectroscopy was also employed to characterize the functionalities in the synthesized NPs within $400-4500 \mathrm{~cm}^{-1}$. The models of equipment used for analyses are shown in supplementary file (SF-1).

\subsection{Preparation of steel specimens}

Owing to its extensive application especially in the construction of pipelines in oilfield, X80 steel (description in SF-2) was used for the study. Coupons were pre-treated in absolute ethanol to remove grease and lubricants, then polished using $\mathrm{SiC}$ abrasives and finished to mirror surface using 2000 grade [5]. Coupons were cleaned with absolute ethanol, dipped in acetone to air-dry and immersed in the prepared test solutions. Coupons for electrochemical experiments were soldered to copper wire and $1 \mathrm{~cm}^{2}$ of the polished surface was exposed while the rest were insulated using epoxy adhesives [5].

\subsection{Preparation of corrosion test solutions}

The blank corrodent was $1.0 \mathrm{M} \mathrm{HCl}$ prepared by dilution of analytical grade $37 \% \mathrm{HCl}$ (description in SF-2) in de-ionized water. Different weights $(\mathrm{mg})$ of the dried Et-ACNPs were 
dissolved in fixed concentration $(1 \mathrm{~L})$ of $1 \mathrm{M} \mathrm{HCl}$ to obtain different concentrations (100-500 mg/L) of Et-AgNPs. As control and basis for comparing the extracts with NPs, $500 \mathrm{mg} / \mathrm{L}$ of dried Et-ACPE was also prepared by dissolving same in $1 \mathrm{M} \mathrm{HCl}$. Before addition of the inhibitor, the $\mathrm{pH}$ of $1 \mathrm{M} \mathrm{HCl}$ was around zero. This $\mathrm{pH}$ value did not change even on addition of the inhibitors. Also, both the extract and NPs were highly soluble in the $1 \mathrm{M} \mathrm{HCl}$ solution.

\subsection{Electrochemical measurements}

The potentiostat/galvanostat was assembled (model and assembly in SF-1) and with the test solutions standing for $30 \mathrm{~min}$ to corrode the steel, stabilize the open circuit potential (OCP) before actual measurement $[5,30]$. The input experimental parameters were as follows: frequency range $=100 \mathrm{kHz}-10 \mathrm{mHz}$ for electrochemical impedance spectroscopy (EIS), voltage range $=-0.15 \mathrm{~V}-+0.15 \mathrm{~V}$ vs. OCP and scan rate $=0.2 \mathrm{mV} / \mathrm{s}$ for potentiodynamic polarization (PDP), frequency pair $=2 \mathrm{~Hz}$ and $5 \mathrm{~Hz}$; base frequency $=0.01 \mathrm{~Hz}$ and amplitude $=10 \mathrm{mV}$ for electrochemical frequency modulation (EFM) and $E_{\text {corr }}= \pm 10 \mathrm{mV}$ and scan rate $=0.25 \mathrm{mV} / \mathrm{s}$ for linear polarization resistance $(\mathrm{LPR})$ at room temperature $\left(30 \pm 2^{\circ} \mathrm{C}\right)[5]$. Gamry E-Chem software was used to analyse data obtained to acquire associated electrochemical parameters. Inhibition efficiency was assessed for EIS $\left(I_{E I S}\right), \operatorname{PDP}\left(I_{P D P}\right), \operatorname{LPR}\left(I_{L P R}\right)$ and EFM $\left(I_{E F M}\right)$ using Eqs. 1, 2, 3 and 4, respectively.

$$
\begin{aligned}
& I_{E I S}=100\left(\frac{R_{c t i}-R_{c t b}}{R_{c t i}}\right) \\
& I_{P D P}=100\left(1-\frac{l_{c \text { corr }}^{i}}{l_{\text {corr }}^{b}}\right) \\
& I_{L P R}=100\left(\frac{R_{P i}-R_{P b}}{R_{P i}}\right) \\
& I_{E F M}=100\left(1-\frac{l_{\text {corr }}^{i}}{l_{\text {corr }}^{b}}\right)
\end{aligned}
$$

where $R_{c t b}$ and $R_{c t i}$ represent charge transfer resistance without and with inhibitor, respectively, $l_{\text {corr }}^{b}$ and $l_{\text {corr }}^{i}$ represent corrosion current density without and with inhibitor, respectively $R_{P i}$ and $R_{P b}$ represent resistance polarization with and without inhibitor, respectively [5].

\subsection{Weight loss measurement}

X80 steel coupons (dimension $3 \mathrm{~cm} \times 3 \mathrm{~cm} \times 0.5 \mathrm{~cm}$ ) were weighed, immersed by suspension method in $100 \mathrm{~mL}$ of blank and inhibitor (crude extracts and NPs) test solutions and sealed to exclude air. The containers were placed in water bath equilibrated to $30^{\circ} \mathrm{C}$ for $6 \mathrm{~h}$ after which they were retrieved and cleaned using ASTM procedures [31] and re-weighed; loss in weights were recorded. Triplicates of experiments were conducted and the mean weight loss $(\Delta w)$ was used to compute corrosion rate $(C R, \mathrm{mmpy})$ according to Eq. 5 [5].

$C R=\frac{87600 \Delta w}{\rho A t}$

where $\rho, A$ and $t$ represent density $\left(\mathrm{gcm}^{-3}\right)$, surface area $\left(\mathrm{cm}^{2}\right)$, and immersion time (h), respectively. Corrosion inhibition efficiency $\left(I_{W}, \%\right)$ was elucidated using Eq. 6.

$I_{W}=100\left(1-\frac{C R_{\text {inh }}}{C R_{H C l}}\right)$

where $C R_{H C l}$ and $C R_{\text {inh }}$ represent corrosion rate in the $1 \mathrm{M}$ $\mathrm{HCl}$ without inhibitor and with inhibitor, respectively. Similar measurements were replicated at 40,50 and $60^{\circ} \mathrm{C}$.

\subsection{Surface and corrosion products}

Surface deposits on the steel coupon after immersion was mechanically peeled off and analysed by FTIR. Elemental composition, surface morphologies, topographies and other surface features of the retrieved steel coupons in both uninhibited and inhibited solutions were investigated by EDS, SEM and AFM as previously described [29].

\section{Results and discussions}

\subsection{Yield of extracts}

The extraction occurred very fast in ethanol and the weight of the residue after drying was found to be $6.7824 \mathrm{~g}$. This means that $3.2176 \mathrm{~g}$ of the phytocompounds dissolved at room temperature and was actually recovered in ethanol. This corresponds to a yield of $32.2 \%$. The intensity of the red colour that initially characterized the powdered peels was found to reduce (in the residue) implying that most of the extractable compounds were sufficiently extracted.

\subsection{Formation and characterization of NPs in comparison with extract}

The formation of NPs was signalled by a change in colour of the mixtures. The colours changed from pale red to reddish brown as shown in Fig. 2, signifying the completion of bio-reduction of the silver ions. The formation of Et-AgNPs occurred within $85 \mathrm{~min}$. Usually, the time taken 
for NPs formation varies from extract to extract even with the same metal ion due to differences in chemical natures and concentrations of the phyto-compounds present and on reaction conditions such as temperature and $\mathrm{pH}$ [15]. Since formation of the NPs occurred fast, it was not necessary to vary the above conditions because of the intended application. The final colour of NPs solution remained unchanged even after being observed for additional $24 \mathrm{~h}$ later. Also, the obtained solution was homogeneous without any sediments, indicating that the AgNPs were highly soluble.

\subsubsection{UV-Vis spectroscopy}

The UV-Vis spectra of Et-ACPE and the corresponding EtAgNPs are displayed in Fig. 3a. Actually, the spectrum of

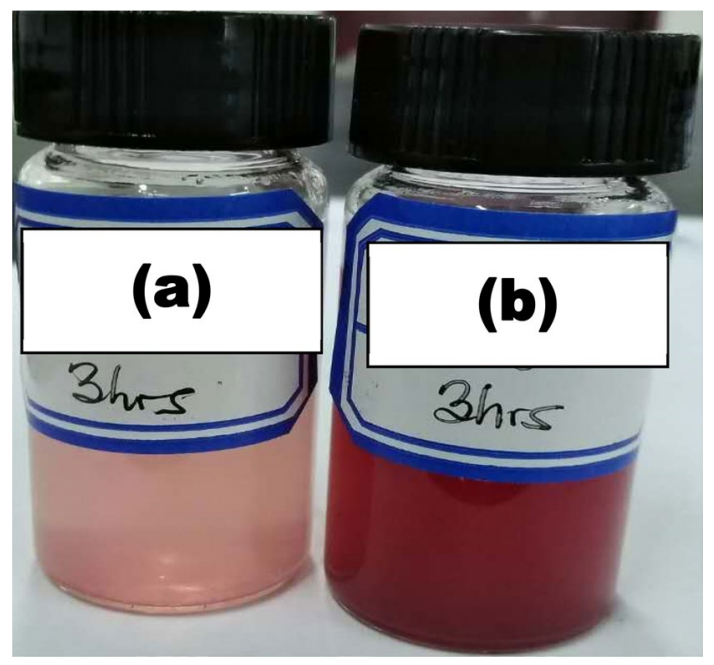

Fig. 2 Colour of a $20 \mathrm{~mL}$ Et-ACPE/100 mL H2O and b $20 \mathrm{~mL}$ ACPE/100 mL AgNO3 (Et-AgNPs) after three hours of formation of NPs the solution was obtained at 10 min interval but only the initial and final spectra are reported. Formation of NPs produced plasmon resonance absorption band at a different wavelength and absorbance value from that of the pure extract. On complete bio-reduction of the $\mathrm{Ag}^{+}$ions, plasmon absorption was observed at $\lambda_{\max }=435 \mathrm{~nm}$, whereas Et-ACPE absorption occurred at $\lambda_{\max }=510 \mathrm{~nm}$. Within the range of the broad absorption of Et-ACPE (475-625 nm), it was observed that the NPs showed no change in absorbance values. Most plant extract mediated silver nanoparticles reported in literature show plasmon absorption around $400-500 \mathrm{~nm}$ as obtained in this study, and this range has been reported to be characteristic of typical $\mathrm{Ag}$ plasmon [30, 31], which supports formation of Et-AgNPs.

\subsubsection{XRD spectroscopy}

XRD diffraction pattern of the pure extract and the NPs obtained is shown in Fig. 3b. It can be observed that the spectrum of Et-ACPE has neither distinct peaks nor diffraction angles whereas the spectrum of Et-AgNPs show up to four (4) main peaks. The diffraction pattern obtained for Et-ACPE matrix can be attributed to its amorphous nature (hence diffraction of glass) and absence of metallic crystal. However, peaks in the spectrum for Et-AgNPs were obtained at $2 \theta=38.01^{\circ}, 45.82^{\circ}, 64.38^{\circ}$, and $77.45^{\circ}$. To confirm whether the obtained peaks and diffraction angles correspond to reference (standard) values for silver crystal structure, the spectra were analysed using X-PERT HighScore Plus software package (PANalytical) [5]. Results confirm that these peaks correspond to $110\left(2 \theta=38.01^{\circ}\right)$, $220\left(2 \theta=45.82^{\circ}\right), 220\left(2 \theta=64.38^{\circ}\right)$ and $311\left(2 \theta=74.45^{\circ}\right)$ Braggs crystallographic planes of face centre cubic (FCC) structure. The sharpness of all the peaks (without broadening) indicates that NPs are devoid of defects in their crystal structure. The standard reference values of $2 \theta$ for silver
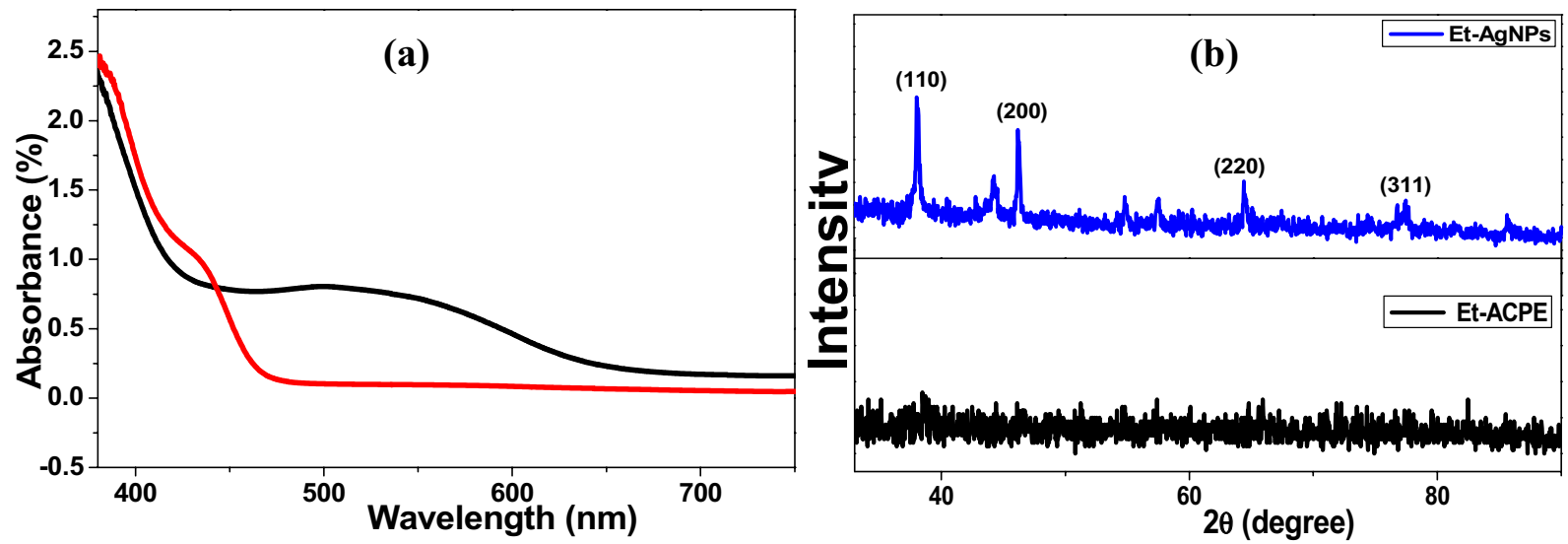

Fig. 3 a UV-Vis spectra of Et-ACPE (black) and Et-AgNPs (red) from ACPE. b X-ray diffraction pattern of Et-ACPE and Et-AgNPs from ACPE 
nanoparticles are $38.162^{\circ}, 44.597^{\circ}, 64.674^{\circ}$ and $77.544^{\circ} 0$ [34]. XRD results also confirmed the existence of silver in the $\mathrm{Ag}^{0}$ phase in the NPs. Results of analyses also show that the Ag atoms in the fcc structure with $a=b=c=4.0968 \AA$ and $\alpha=\beta=\gamma=90^{\circ}$, contain cells with volumes $72.43 \times 10^{-6}$ $\mathrm{pm}^{3}$ and density $(\rho) 10.18 \mathrm{gcm}^{-3}$. Peak intensity was very high at $2 \theta=38.01^{\circ}$ implying that the preferred orientation of Et-AgNPs is the (111) plane [32, 33].

\subsubsection{SEM/EDS}

To further confirm that NPs were formed, and to elucidate the shapes of the NPs, SEM images of morphologies of both Et-ACPE and Et-AgNPs were obtained as shown in Fig. 4 (top). It was necessary to select a higher magnification for the NPs to be visible because of their small sizes. Also, the elements composing the surfaces were detected by obtaining EDS spectra of the extract and NPs surfaces as also shown in Fig. 4 (bottom). SEM results also confirmed the amorphous and crystalline morphology of EtACPE and Et-AgNPs, respectively. The NPs were spherical in shape and did not agglomerate or aggregate, although some traces of uncapped phyto-compounds were visible around0 the surface of the NPs. Other authors have also reported similar observations $[34,35]$.

EDS scan at the spots corresponding to the extract and particles surfaces reveal that only Et-AgNPs contained silver. Bio-reduction of $\mathrm{Ag}^{+}$ions by Et-ACPE is associated with capping of the phytocompounds on silver. Consequently, the amount of $C$ (atom \%) on the NPs surface decreases from $70.12 \%$ to $46.54 \%$ whereas the amount of surface $\mathrm{O}$ (atom \%) increases from 27.65 to $36.81 \%$. There was no significant increase in the amount of $\mathrm{N}$ atoms-which was found to be $2.23 \%$ to $2.25 \%$ for Et-ACPE and Et-AgNPs respectively. The amount of $\mathrm{Ag}$ (atom \%) composing the Et-ACPE and Et-AgNPs was $0 \%$ and $14.40 \%$ showing that $\mathrm{Ag}$ atoms were incorporated into the matrix to form AgNPs. Since $O$ sites are rich in electron cloud, it can be predicted that the NPs surface would exhibit greater electron cloud than the extracts. Greater electron cloud due to more $\mathrm{O}$ sites would increase the adsorptive capacity of the NPs compared to the extracts. This presents great prospects for the synthesized nanoparticles to find application in adsorption related phenomena such as removal of heavy metals, corrosion and scale inhibition, and as adsorbents for water treatment, which we are still investigating.
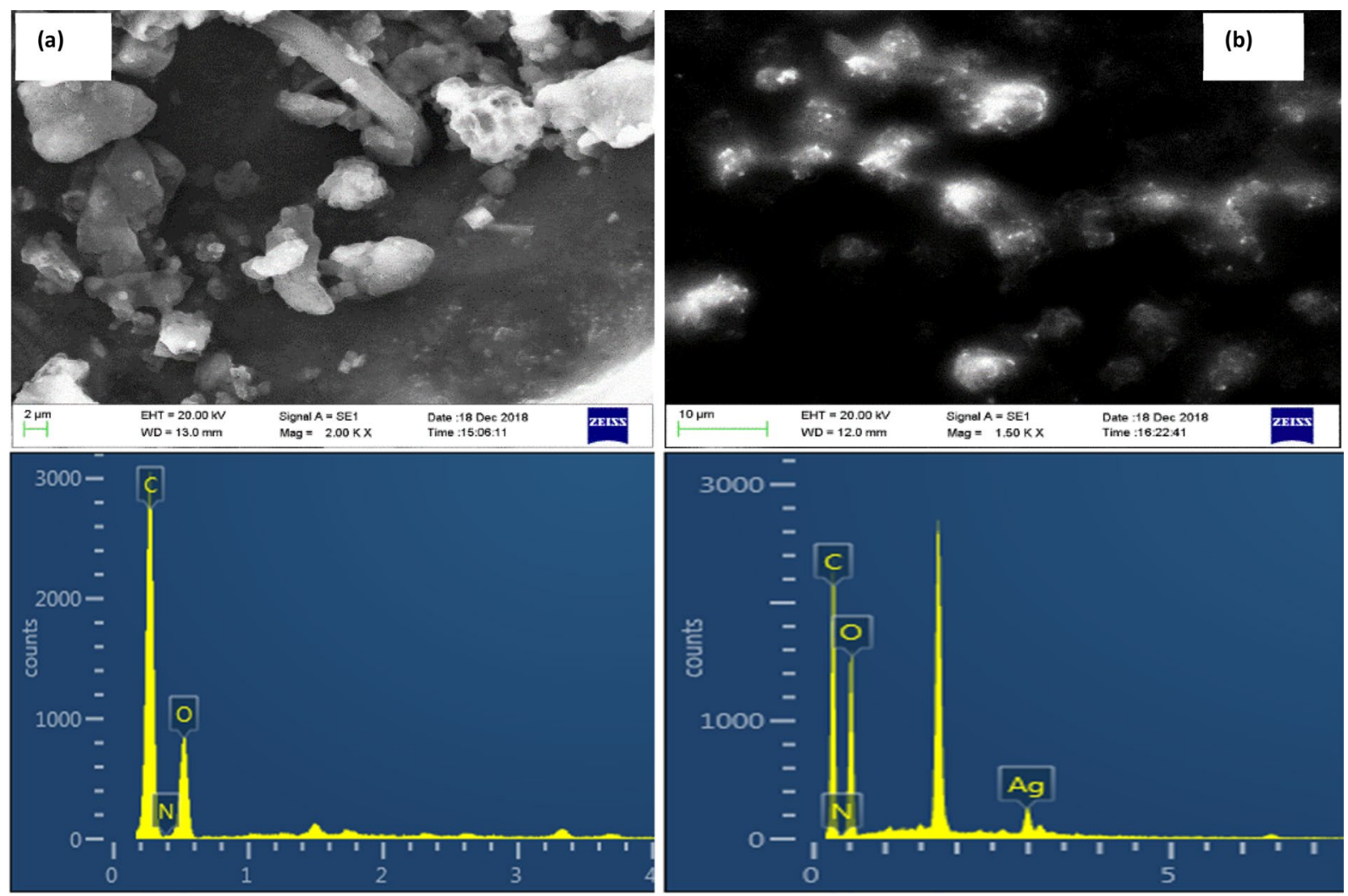

Fig. 4 Top: SEM images of morphologies and; Bottom: EDS profiles of elemental composition of dried a Et-ACPE and $\mathbf{b}$ Et-AgNPs as observed by SEM

\section{SN Applied Sciences




\subsubsection{TEM}

The NPs size and morphology were checked by transmission electron microscopy, TEM (Fig. 5a). It can be implied from results that non-aggregated nanoscale particles of almost non-uniform shapes and sizes were formed. The particles were predominantly spherical in shape and distributed between 20 and $50 \mathrm{~nm}$ in size. This size is comparable to those reported for other phyto-mediated silver nanoparticles [16]. However, the size of biosynthesized NPs is usually influenced by some factors such as concentrations of the extract and $\mathrm{AgNO}_{3}, \mathrm{pH}$, incubation time and volume of extract. Around the nanoparticles, some organic-based materials from the uncapped extracts were also seen just as in SEM/EDS results.

\subsubsection{DLS}

The zeta potential, polydispersity index, hydrodynamic size and size distribution were obtained via DLS measurements. Average zeta potential of the colloidal NPs determined with alcohol as dispersant was found to be $-46.2 \pm 0.2 \mathrm{mV}$. The high magnitude of this zeta potential points to high degree of Coulombic or electrostatic repulsion between highly negatively charged adjacent nanoparticles in the colloidal dispersion which enhances stabilization of the NPs and prevents agglomeration [36, 37]. Although the value obtained is comparably higher than some other plants mediated silver nanoparticles previously reported, it is an indication that the colloidal NPs were highly electrically stabilized, hence highly resistant to aggregation. A higher proportion of the particles were found to be distributed around $78-86 \mathrm{~nm}$ hydrodynamic size (Fig. 5b), slightly larger than sizes obtained by TEM analyses but still within the range for nanoparticles. The difference in the size measured by TEM and DLS is indicative of agglomeration state: agglomerated particles will show much larger sizes by DLS than TEM measurements [38]. However, similar or slightly larger particle sizes from DLS than TEM measurements show that the particles did not agglomerate. In addition, the average polydispersity index (PDI) value was 0.38 indicating that the NPs are almost monodisperse and very stable [39].

\subsubsection{FTIR}

The FTIR spectrum of the Et-AgNPs was similar to that of Et-ACPE (Fig. 6) but with slight shifts in wave numbers of the absorption peaks, which is characteristic of most plant mediated silver nanoparticles ${ }^{40}$. For the extracts, prominent peaks were observed at 710, 1050, 1350, 1620,2930 and $3300-3500 \mathrm{~cm}^{-1}$. However, for the NPs, these peaks were found at $680,1120,1400,1650$, and $3440 \mathrm{~cm}^{-1}$. The peak at $2930 \mathrm{~cm}^{-1}$ which may be assigned to either $-\mathrm{CH}_{2}$ or $\mathrm{C}-\mathrm{CH}_{3}$ stretching vibrations were found to have disappeared on formation of the NPs. Instead of the broad peak between 3300 and $3500 \mathrm{~cm}^{-1}$ obtained with the extract, the NPs produced a sharp intense peak at $3440 \mathrm{~cm}^{-1}$ [40]. The broad peak represents intermolecular hydrogen bonded - $\mathrm{OH}$ stretching vibrations but can also represent $-\mathrm{N}-\mathrm{H}$ stretching vibrations. $\mathrm{N}-\mathrm{H}$ stretching vibrations usually produce a sharp single intense peak at $3300-3500 \mathrm{~cm}^{-1}$ as obtained in the spectrum of the NPs. However, EDS analyses earlier showed that there were no $\mathrm{N}$ atoms on the NPs surface and previous HPLC-MS had shown that major compounds in Et-ACPE contain more of $-\mathrm{OH}$ group [41], hence this peak can be solely assigned to $-\mathrm{O}-\mathrm{H}$ vibrations. The peak at $1650 \mathrm{~cm}^{-1} \mathrm{can}$ be due to $\mathrm{C}=\mathrm{O}$ stretching in carboxylic acids or stretching vibrations due to non-conjugated $\mathrm{C}=\mathrm{C}$ moiety. Also, $\mathrm{C}-\mathrm{O}$ stretch in lactam, $\mathrm{N}-\mathrm{H}$ amine, $\mathrm{C}=\mathrm{C}$ stretching in cyclic alkenes or $\alpha, \beta$-unsaturated ketones can give rise to the peak at $1650 \mathrm{~cm}^{-1}$. In the fingerprint region, The peak at $1400 \mathrm{~cm}^{-1}$ represents $\mathrm{C}-\mathrm{O}$ stretching vibrations; the one
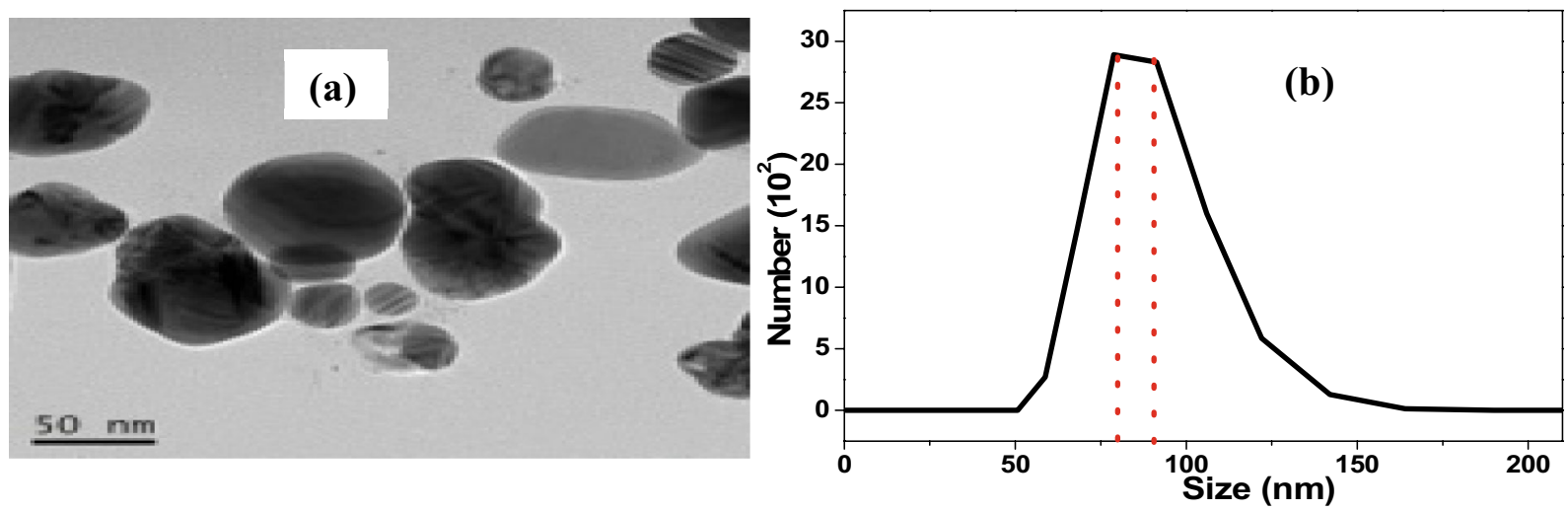

Fig. 5 a TEM images of Et-AgNPs and $\mathbf{b}$ Distribution of hydrodynamic size of Et-AgNPs by DLS intensity measurement 
Fig. 6 a FTIR spectra obtained for Et-ACPE (black) and EtAgNPs (red); b FTIR spectra obtained for pure Et-AgNPs (black) and surface adsorbed Et-AgNPs (red) on X80 steel
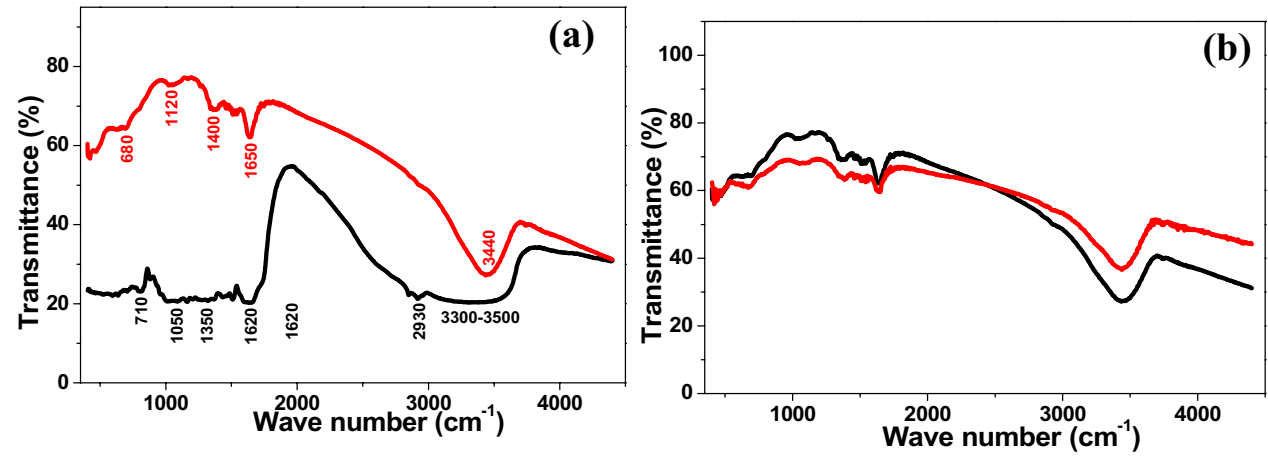

at $1050 \mathrm{~cm}^{-1}$ can be assigned to $\mathrm{C}-\mathrm{OH}$ vibrations of secondary cyclic alcohols while the peak at 710 represents - $\mathrm{CH}$ out of plane bending vibrations in ethylenic systems, especially $-\mathrm{CH}=\mathrm{CH}-[5,42]$ and was found to have been involved in interaction with silver ions.

\subsection{Corrosion studies}

\subsubsection{EIS}

This measurement was performed to probe how addition of the NPs influences the corrosion process, its mechanism
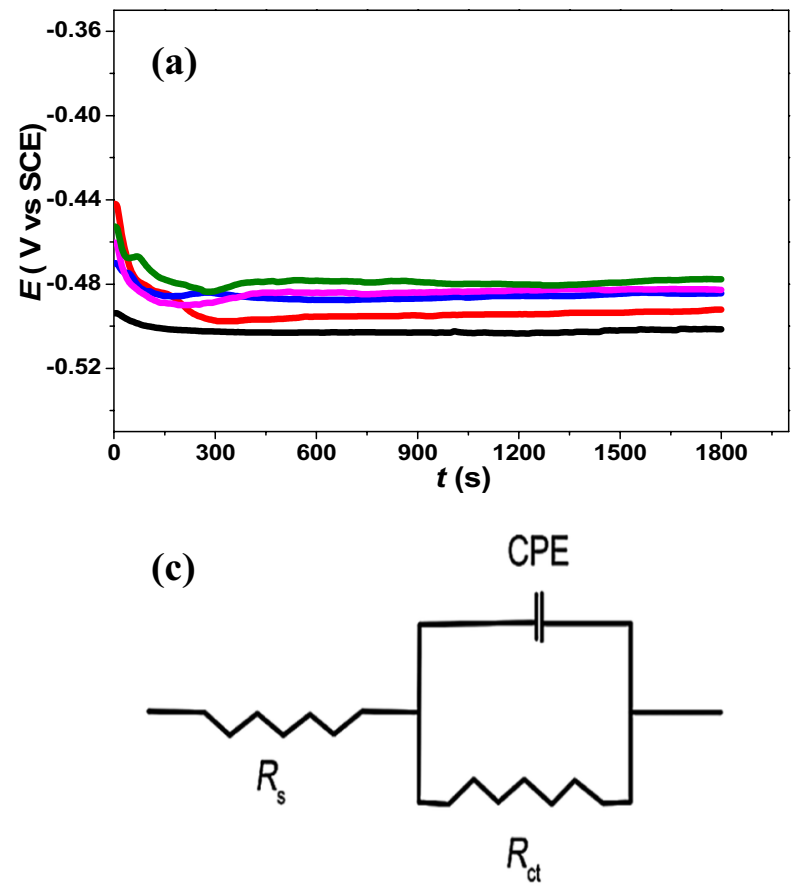

Fig. 7 a OCP vs time plot b Nyquist plot and c Equivalent circuit used to fit data and $\mathbf{d}$ Tafel plot for the corrosion of X80 steel in blank $1 \mathrm{M} \mathrm{HCl}$ and $1 \mathrm{M} \mathrm{HCl}$ inhibited using Et-ACPE and Et-AgNPs. and capacitive response at the steel-acid interface. The OCP was found to stabilize within $450 \mathrm{~s}$ (Fig. 7a) indicating corrosion measurements can be accurately taken. However, with respect to the blank acid, OCP shifts to positive values in the presence of the inhibitors. Based on this observation, the additives may be considered as being anodic inhibitor. Impedance data obtained were used to construct Nyquist plots shown in Fig. $7 \mathrm{~b}$ and the plots were analysed by fitting using a simple CPE equivalent circuit model shown in Fig. 7c which afforded good fitness in the order of $10^{-4}$. The obtained EIS parameters are displayed in Table 1. All the plots (both the blank and

\section{SN Applied Sciences}
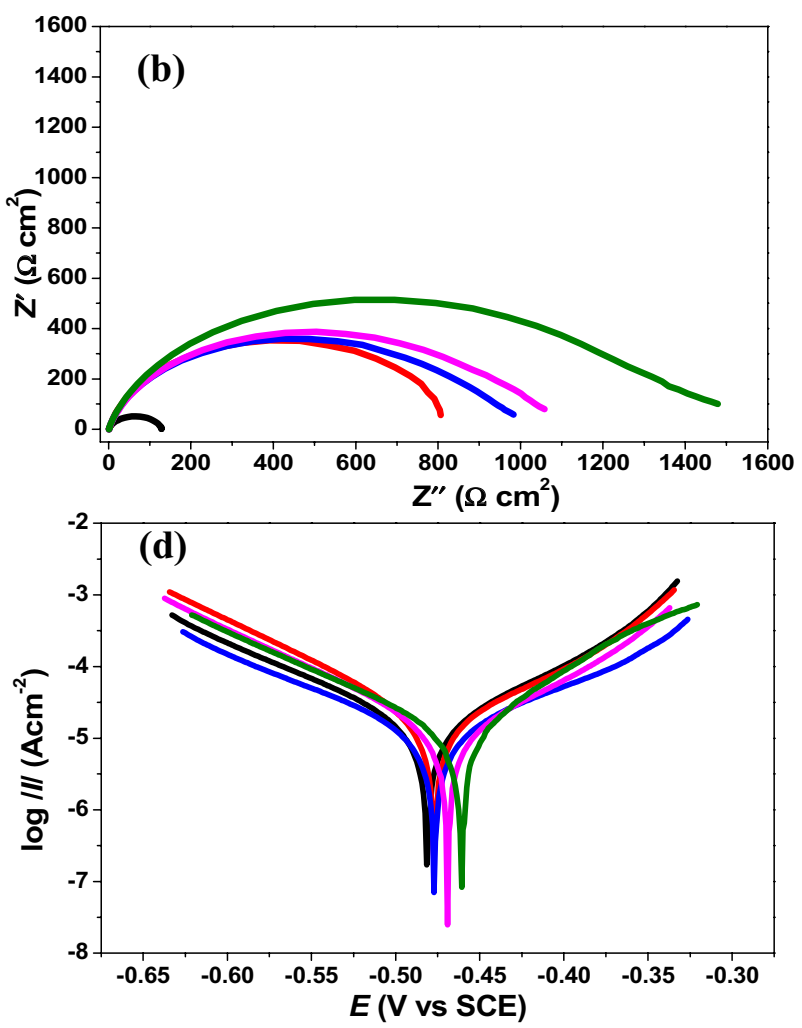

Key: Black $=1 \mathrm{M} \mathrm{HCl}$; red $=500 \mathrm{mg} / \mathrm{L} \mathrm{Et}-\mathrm{ACPE} ;$ blue $=100 \mathrm{mg} / \mathrm{L} \mathrm{Et}-$ AgNPs; purple $=200 \mathrm{mg} / \mathrm{L}$ Et-AgNPs; green $=500 \mathrm{mg} / \mathrm{L} \mathrm{Et-AgNPs)}$ 
the inhibited solutions) yielded single semicircles indicating that single charge transfer process occurred at the interface. Similarity in shape of the semicircles also indicates similar corrosion mechanism despite addition of the inhibitors. Thus, addition of inhibitors has no significant influence on the corrosion mechanism of X80 steel in $1 \mathrm{M}$ $\mathrm{HCl}$ solution. As the concentration of NPs was increased, both charge transfer resistance and inhibition efficiency increased in magnitude. The magnitude of the calculated double layer capacitance $\left(C_{d l}\right)$ was highest in the blank acid solution, and decreased with increase in Et-AgNPs concentration. This is a consequence of increase in the local dielectric constant or insulation property at the interface due to inhibitor adsorption ${ }^{29}$. Also, as concentration of the NPs increases, $C_{d l}$ decreases, the insulating effect of the surface layer increases due to increased adsorption of more Et-AgNPs.

\subsubsection{PDP}

Tafel plots (Fig. 7d) were constructed from polarization data and the effect of addition of different concentrations of the NPs on the cathodic and anodic half reactions was investigated. Addition of the NPs decreased the corrosion current density $\left(I_{\text {corr }}\right)$, and consequently, the corrosion rate. The obtained $l_{\text {corr }}$ values (Table 2 ) decreased as concentration of NPs increased, and the Tafel slopes were also altered. Increasing the Et-AgNPs concentration also resulted in higher inhibition efficiency and the magnitude and trend of efficiency was similar and comparable to EIS results. For all the nanoparticles solutions, the slopes of the anodic branches and the corresponding anodic Tafel constant $\left(\beta_{c}\right)$ values were highly displaced compared to those of the cathodic branches and constants $\left(\beta_{a}\right)$. This establishes that the NPs has dominating effect or impact on anodic than cathodic reaction [29]. It was also observed that $E_{\text {corr }}$ values shift towards more positive values, also depicting dominant anodic influence and thus supporting the trend of the Tafel constants. Based on these observations, it could be implied that Et-AgNPs influences more of the anodic reaction than cathodic reaction. This trend is in agreement with OCP measurement. However, since the displacement in $E_{\text {corr }}$ values is less than $0.85 \mathrm{~V}$, the NPs can be categorized as mixed type inhibitor with anodic predominance [43-45].

\subsubsection{EFM}

EFM measurement afforded complementary results to EIS and PDP and to further afforded corrosion current values via small signals. The efficiency of corrosion inhibition (Table 3) was computed from the corrosion current values. As obtained with impedance and polarization measurements, inhibition efficiency increased as NPs concentration increased. Furthermore, causality factors, CF-2 and CF-3 were obtained and all the values were approximate to theoretical values of 2 and 3 respectively, indicating good quality of measurements $[46,47]$. The Tafel constants $\left(\beta_{a}\right.$ and $\beta_{c}$ ) constants were also obtained, and as observed in PDP results, there was more spread in $\beta_{a}$ than $\beta_{c}$ values, supporting more impact on the anodic than cathodic half reaction.

\subsubsection{LPR}

LPR experiment was carried out to further support the inhibition efficiency obtained from prior electrochemical measurements. The Stern-Geary equation (Eq. 7) was used to estimate polarization resistance, and used to compute inhibition efficiency.
Table 1 EIS parameters for the inhibition of $\mathrm{X} 80$ steel corrosion in $1 \mathrm{M} \mathrm{HCl}$ containing Et-ACPE and different concentrations of its Et-AgNPs

\begin{tabular}{lllllll}
\hline Test solution & $R_{s}(\Omega)$ & $R_{c t}(\Omega)$ & $n$ & $C_{d I}\left(\mu \mathrm{Fcm}{ }^{-2}\right)$ & $I_{\text {EIS }}(\%)$ & $\chi^{2} 10^{-4}$ \\
\hline Blank & $0.864 \pm 0.012$ & $128.8 \pm 1.3$ & 0.844 & 26.72 & - & 1.08 \\
$500 \mathrm{mg} / \mathrm{L} \mathrm{ACPE}$ & $0.918 \pm 0.018$ & $800.2 \pm 3.8$ & 0.846 & 11.04 & $83.9 \pm 1.1$ & 1.07 \\
$100 \mathrm{mg} / \mathrm{L} \mathrm{AgNPs}$ & $1.024 \pm 0.021$ & $1070.6 \pm 5.7$ & 0.857 & 5.13 & $88.0 \pm 1.7$ & 3.11 \\
$200 \mathrm{mg} / \mathrm{L} \mathrm{AgNPs}$ & $1.108 \pm 0.016$ & $1187.9 \pm 9.6$ & 0.863 & 2.02 & $89.2 \pm 1.6$ & 3.09 \\
$500 \mathrm{mg} / \mathrm{L} \mathrm{AgNPs}$ & $1.241 \pm 0.011$ & $1576.4 \pm 11.4$ & 0.881 & 0.74 & $91.8 \pm 2.2$ & 2.94 \\
\hline
\end{tabular}

Table 2 PDP parameters for the inhibition of X80 steel corrosion in $1 \mathrm{M} \mathrm{HCl}$ containing Et-ACPE and different concentrations of its Et-AgNPs

\begin{tabular}{lllllc}
\hline Test solution & $I_{\text {corr }}\left(\mathrm{Acm}^{-2}\right)$ & $E_{\text {corr }}(\mathrm{V})$ & $\beta_{a}\left(\mathrm{mVdec}^{-1}\right)$ & $\beta_{c}\left(\mathrm{mVdec}^{-1}\right)$ & $I_{P D P}(\%)$ \\
\hline Blank & $996.1 \pm 2.8$ & $-0.489 \pm 0.006$ & 151.4 & -144.7 & - \\
$500 \mathrm{mg} / \mathrm{L} \mathrm{ACPE}$ & $176.8 \pm 1.6$ & $-0.480 \pm 0.005$ & 141.3 & -140.2 & $82.3 \pm 1.5$ \\
$100 \mathrm{mg} / \mathrm{L} \mathrm{AgNPs}$ & $142.4 \pm 2.1$ & $-0.476 \pm 0.004$ & 130.8 & -138.6 & $85.7 \pm 1.3$ \\
$200 \mathrm{mg} / \mathrm{L} \mathrm{AgNPs}$ & $124.1 \pm 0.8$ & $-0.468 \pm 0.007$ & 118.4 & -135.2 & $87.5 \pm 1.2$ \\
$500 \mathrm{mg} / \mathrm{L}$ AgNPs & $80.7 \pm 1.2$ & $-0.460 \pm 0.008$ & 102.6 & -128.1 & $91.9 \pm 1.3$ \\
\hline
\end{tabular}


Table 3 EFM parameters for the inhibition of $\mathrm{X} 80$ steel corrosion in $1 \mathrm{M} \mathrm{HCl}$ containing ACPE and different concentrations of its Et-AgNPs

\begin{tabular}{llllllc}
\hline Test solution & $\beta_{a}\left(\right.$ mVdec $\left.^{-1}\right)$ & $\beta_{c}\left(\right.$ mVdec $\left.^{-1}\right)$ & $C F-2$ & $C F-3$ & $I_{\text {corr }}\left(\right.$ Acm $\left.^{-2}\right)$ & $I_{\text {EFM }}(\%)$ \\
\hline Blank & 133.8 & -112.7 & 2.011 & 2.962 & $861.3 \pm 4.4$ & - \\
$500 \mathrm{mg} / \mathrm{L} \mathrm{ACPE}$ & 121.4 & -109.9 & 1.992 & 3.011 & $162.4 \pm 1.7$ & $81.1 \pm 1.3$ \\
$100 \mathrm{mg} / \mathrm{L} \mathrm{AgNPs}$ & 107.2 & -106.1 & 1.996 & 2.984 & $141.7 \pm 1.6$ & $83.5 \pm 1.2$ \\
$200 \mathrm{mg} / \mathrm{L} \mathrm{AgNPs}$ & 94.8 & -104.8 & 1.981 & 2.976 & $106.5 \pm 0.8$ & $87.6 \pm 1.2$ \\
$500 \mathrm{mg} / \mathrm{L} \mathrm{AgNPs}$ & 91.6 & -97.6 & 1.968 & 3.004 & $64.3 \pm 1.1$ & $92.5 \pm 1.4$ \\
\hline
\end{tabular}

Table 4 LPR parameters for the inhibition of X80 steel corrosion in $1 \mathrm{M} \mathrm{HCl}$ containing ACPE and different concentrations of its EtAgNPs

\begin{tabular}{lcc}
\hline Test solution & \multicolumn{1}{c}{$R_{P}(\Omega)$} & $I_{P D P}(\%)$ \\
\hline Blank & $104.2 \pm 3.1$ & - \\
$500 \mathrm{mg} / \mathrm{L} \mathrm{ACPE}$ & $558.4 \pm 4.7$ & $81.3 \pm 2.4$ \\
$100 \mathrm{mg} / \mathrm{L}$ AgNPs & $639.6 \pm 5.2$ & $83.7 \pm 1.6$ \\
$200 \mathrm{mg} / \mathrm{L}$ AgNPs & $784.1 \pm 4.2$ & $86.7 \pm 1.1$ \\
$500 \mathrm{mg} / \mathrm{L}$ AgNPs & $1189.4 \pm 13.6$ & $91.2 \pm 1.2$ \\
\hline
\end{tabular}

$R_{p}=\frac{\beta_{a} \beta_{c}}{2.303 I_{\text {corr }}\left(\beta_{a}+\beta_{c}\right)}$

The $R_{p}$ and inhibition efficiency values obtained (Table 4) also increased as NPs concentration increased, similar to trends obtained for other measurements. Also, polarization resistance increases with the solutions inhibited by the NPs than the crude extract supporting that adsorption of the NPs resulted in increased resistance around the electrode surface, depicting increased surface insulation. The results obtained for LPR also follow similar trend as other EIS, PDP and EFM measurements.

\subsubsection{Weight loss}

Loss in weight and corrosion rate of X80 steel coupons in the blank $1 \mathrm{M} \mathrm{HCl}$ and containing both Et-ACPE and Et-AgNPs were measured by weight loss experiments and results were compared. The obtained data of weight loss and corrosion rate are presented in Table 5. Weight loss, and consequently corrosion rate, was highest in the blank acid solution, but reduced on addition of the extract and NPs. In comparison, the NPs offered higher inhibition efficiency and were more thermally stable than the crude extracts. Thus, an equivalent concentration of the NPs was more efficient than Et-ACPE at all temperatures studied (see Table 5). In fact, a very low concentration of the NPs ( $100 \mathrm{mg} / \mathrm{L})$ exhibited higher efficiency than $500 \mathrm{mg} / \mathrm{L} \mathrm{Et}$ ACPE. This demonstrates that processing the extract into NPs enhances their anticorrosion behaviour, perhaps due to improved adsorption capacity and the presence of more electron cloud around $\mathrm{O}$ atoms (according to EDS results) for adsorption on the steel surface. Efficiency of inhibition increases as NPs concentration increases and was fairly stable at as temperature increases compared to the extract. In terms of $\mathrm{pH}$, addition of the extract and nanoparticles to a fixed volume of $1 \mathrm{M} \mathrm{HCl}$ did not influence the $\mathrm{pH}$ of the test solutions. Thus, it may be considered that the acid remained in the live form even in the presence of the additives. This also implies that the additives did not reduce or increase the acidity of $1 \mathrm{M} \mathrm{HCl}$.

\subsubsection{Kinetics, thermodynamics and adsorption mechanistic studies}

Like most chemical reactions, the rate of corrosion increases as temperature increases. The presence of the NPs reduced corrosion rate of X80 steel. Corrosion rate data was used to construct linearized plots shown in Fig. $8 \mathrm{a}$ and $\mathrm{b}$ based on Arrhenius equation (Eq. 8) and transition state equation (Eq. 9), respectively $[48,49]$.

Table 5 Weight loss, corrosion rate and inhibition efficiency of Et-ACPE and Et-AgNPs against X80 steel corrosion in $1 \mathrm{M} \mathrm{HCl}$ at $30-60{ }^{\circ} \mathrm{C}$

\begin{tabular}{|c|c|c|c|c|c|c|c|c|c|c|c|c|}
\hline \multirow[t]{2}{*}{ Test solution } & \multicolumn{3}{|l|}{$30^{\circ} \mathrm{C}$} & \multicolumn{3}{|l|}{$40^{\circ} \mathrm{C}$} & \multicolumn{3}{|l|}{$50^{\circ} \mathrm{C}$} & \multicolumn{3}{|l|}{$60^{\circ} \mathrm{C}$} \\
\hline & $\Delta w(\mathrm{~g})$ & CR mmpy & $I_{w}(\%)$ & $\Delta w(\mathrm{~g})$ & CR mmpy & $I_{w}(\%)$ & $\Delta w(\mathrm{~g})$ & CR mmpy & $I_{w}(\%)$ & $\mathrm{s}(\mathrm{g})$ & CR mmpy & $I_{w}(\%)$ \\
\hline Blank & 0.0563 & 12.22 & - & 0.0864 & 18.74 & - & 0.1402 & 30.41 & - & 0.2363 & 51.18 & - \\
\hline $500 \mathrm{mg} / \mathrm{L} \mathrm{ACPE}$ & 0.0104 & 2.26 & $81.5 \pm 1.2$ & 0.0188 & 4.07 & $78.3 \pm 0.6$ & 0.0356 & 7.72 & $74.6 \pm 1.1$ & 0.0717 & 15.56 & $69.6 \pm 1.3$ \\
\hline $100 \mathrm{mg} / \mathrm{L} \mathrm{AgNPs}$ & 0.0091 & 1.98 & $83.8 \pm 0.9$ & 0.0169 & 3.67 & $80.4 \pm 0.6$ & 0.0320 & 6.93 & $77.2 \pm 0.8$ & 0.0592 & 12.85 & $74.9 \pm 1.1$ \\
\hline 200 mg/L AgNPs & 0.0072 & 1.56 & $87.2 \pm 0.6$ & 0.0119 & 2.59 & $86.2 \pm 0.4$ & 0.0227 & 4.93 & $83.8 \pm 0.6$ & 0.0493 & 10.70 & $79.1 \pm 0.9$ \\
\hline $500 \mathrm{mg} / \mathrm{L} \mathrm{AgNPs}$ & 0.0036 & 0.78 & $93.6 \pm 0.7$ & 0.0075 & 1.63 & $91.3 \pm 0.7$ & 0.0155 & 3.37 & $88.9 \pm 1.2$ & 0.0373 & 8.09 & $84.2 \pm 0.8$ \\
\hline
\end{tabular}


$\log C R=\log Z-\frac{E_{a}}{2.303 R T}$

$\log \left(\frac{C R}{T}\right)=\left[\left(\log \left(\frac{R}{N h}\right)+\left(\frac{\Delta S^{*}}{2.303 R}\right)\right)\right]-\left(\frac{\Delta H^{*}}{2.303 R T}\right)$

where $C R$ is the corrosion rate, $Z$ the Arrhenius pre-exponential or frequency factor, $R$ is the universal gas constant, $N$ is Avogadro's number, $T$ is absolute temperature, $\Delta H^{*}$ and $\Delta S^{*}$ is the enthalpy and entropy change of activation respectively [45].

Activation energy was determined from the Arrhenius plots while enthalpy and entropy changes were deduced from transition state plots. Results reveal that activation energy was lowest in the free acid medium and increased on addition and with increasing Et-AgNPs concentration (Table 6). The activation energy obtained with the blank acid solution could be considered as the minimum energy with which the acid molecules must generate for effective collision on the steel surface to cause its corrosion. Therefore, in the presence of the NPs, the collision of the acid molecules with the steel surface acid must generate higher energy than with the blank, hence corrosion inhibition. Addition of the NPs increase this minimum energy or energy barrier and limits the number of successful collisions that could have resulted to corrosive attack. This trend of activation energy is often associated with physical adsorption mechanism involving electrostatic interaction of charged inhibitor groups with charged species on steel surface $[50,51]$. Adsorption of NPs on X80 steel surface was found to be exothermic and resulted in decrease in entropy of the solution, similar to other steel corrosion inhibitors [5].

The mechanism of adsorption of the NPs on the steel surface and subsequent corrosion inhibition was studied by means of adsorption isotherms. The surface coverage data for various concentrations (mg/L) of Et-AgNPs were used to plot various adsorption isotherms but the
Table 6 Activation parameters for the inhibition of X80 steel corrosion in $1 \mathrm{M} \mathrm{HCl}$ containing different concentrations of Et-AgNPs

\begin{tabular}{|c|c|c|c|c|}
\hline Test solution & $E_{a}\left(\mathrm{kJmol}^{-1}\right)$ & $A\left(\times 10^{9}\right)$ & $-\Delta H\left(\mathrm{kJmol}^{-1}\right)$ & $\Delta S\left(\mathrm{kJmol}^{-1}\right)$ \\
\hline Blank & 39.64 & 0.08 & 37.92 & 0.28 \\
\hline $\begin{array}{c}500 \mathrm{mg} / \mathrm{L} \\
\mathrm{ACPE}\end{array}$ & 40.20 & 0.05 & 38.22 & 0.24 \\
\hline $\begin{array}{c}100 \mathrm{mg} / \mathrm{L} \\
\text { AgNPs }\end{array}$ & 53.60 & 0.04 & 39.02 & 0.23 \\
\hline $\begin{array}{c}200 \mathrm{mg} / \mathrm{L} \\
\mathrm{AgNPs}\end{array}$ & 58.11 & 0.02 & 43.48 & 0.19 \\
\hline $\begin{array}{c}500 \mathrm{mg} / \mathrm{L} \\
\text { AgNPs }\end{array}$ & 63.47 & 0.01 & 47.92 & 0.13 \\
\hline
\end{tabular}

Langmuir isotherm afforded the best fit $\left(R^{2} \geq 0.9995\right)$. The mathematical expression for this model is given in Eq. 10 and can be related with free energy of adsorption $\left(\Delta G_{a d s}\right)$ by Eq. 11 [5].

$\frac{C_{N P s}}{\theta}=\frac{1}{K_{a d s}}+C_{N P s}$

$\Delta G_{a d s}=-R T \ln 55.5 K_{a d s}$

where $C_{N P s}$ is the concentration of the NPs (mg/L), $\theta$ is the fractional surface coverage evaluated by multiplying inhibition efficiency by $0.01, K_{\text {ads }}$ is the adsorption-desorption equilibrium constant, $R$ is the universal gas constant and $T$ is the absolute temperature [52]. Values of $K_{\text {ads }}$ obtained decreased as temperature increases indicating that the equilibrium shifts in favour of desorption of NPs molecules as temperature increases. Thus, increase in temperature decreases the inhibitor-steel surface binding strength. $\Delta G_{\text {ads }}$ values were all negative, and between -21.52 $\mathrm{kJmol}^{-1}$ to $-34.28 \mathrm{kJmol}^{-1}$, indicating that adsorption of the NPs occurs spontaneously, just like many other adsorption processes. Also, the values are less negative than -40 $\mathrm{kJmol}^{-1}$ indicating physical adsorption mechanism [53]. This involves basically electrostatic interaction between
Fig. 8 a Arrhenius plot and $\mathbf{b}$ Transition state plot for the corrosion of steel in $1 \mathrm{M} \mathrm{HCl}$ without and with Et-ACPE and Et-AgNPs. Key: Black = $1 \mathrm{M}$ $\mathrm{HCl}$; red $=500 \mathrm{mg} / \mathrm{L}$ Et-ACPE; blue $=100 \mathrm{mg} / \mathrm{L} \mathrm{Et-AgNPs}$; purple $=200 \mathrm{mg} / \mathrm{L} \mathrm{Et-AgNPs;}$ green $=500 \mathrm{mg} / \mathrm{L} \mathrm{Et}$-AgNPs)
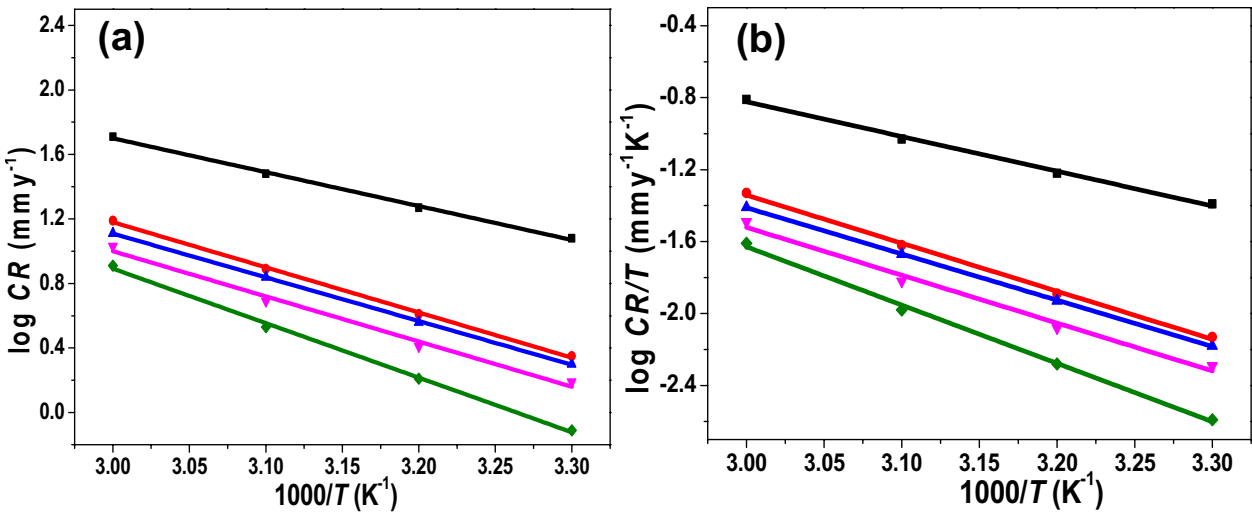

SN Applied Sciences A SPRINGER NATURE journa 
charged species in the inhibitor and the steel surface [47]. Since silver in the NPs is zero-valent, this interaction can possibly occur between the phytoconstituents (capped to the silver) and the steel surface. Each particle could be considered to be composed of one or more capped phyto-compounds containing electron rich site(s) such as $\mathrm{O}$ and $\mathrm{C}=\mathrm{C}$, which can interact with $\mathrm{Fe}$ ions on steel surface. Thus, the nanoparticles enhance the adsorption of more capped phyto-compounds on Fe surface resulting in enhanced corrosion inhibition.

\subsection{Stability of Et-AgNPs}

The stability of the NPs with aging was estimated for 16 weeks of preparation at different temperatures using weight loss measurement. Prior to this, already prepared samples were stored in laboratory cupboards inside reagent bottles at room temperature. The efficiency of the highest concentrations each of Et-AgNps and Et-ACPE were tested by weight loss method every two weeks (from the date they were initially prepared) at the studied temperatures. Results (Fig. 9) show that the efficiency of EtACPE started to decline after 6 weeks, but the NPs were still as efficient throughout the period. The decline in efficiency of the extract was worse at $60^{\circ} \mathrm{C}$. This can be explained in terms of ease of thermal and biodegradation: biochemical degradation of the extract could have easily started within this period, whereas the NPs were stable and did not biodegrade within the time under consideration.

\subsection{Examination of corrosion products}

\subsubsection{FTIR}

After $6 \mathrm{~h}$ of immersion, the retrieved steel coupon was cleaned, air-dried and a thin film observed on its surface was removed by mechanical scrapping and investigated by FTIR. The FTIR spectra of the NPs and the surface film (Fig. 6b) were similar in terms of peak positions and intensity of absorption. This demonstrates that the surface film represents adsorbed Et-AgNPs. Also, since there were only slight changes in peak positions, it can be assumed that there was interaction between the NPs and steel surface, but the adsorptive interaction did not result in the formation of actual chemicals bonds. Therefore, the inhibitor-surface interaction can be considered as physical in nature involving either electrostatic interactions between charged species or involving weak van der Waals interactive forces between surface species and inhibitor sites. Such interactions signify physical adsorption mechanism thus supporting earlier predictions made. Slight displacement in the position of the peak around $680 \mathrm{~cm}^{-1}$ to $650 \mathrm{~cm}^{-1}$ was observed and this could represent complex
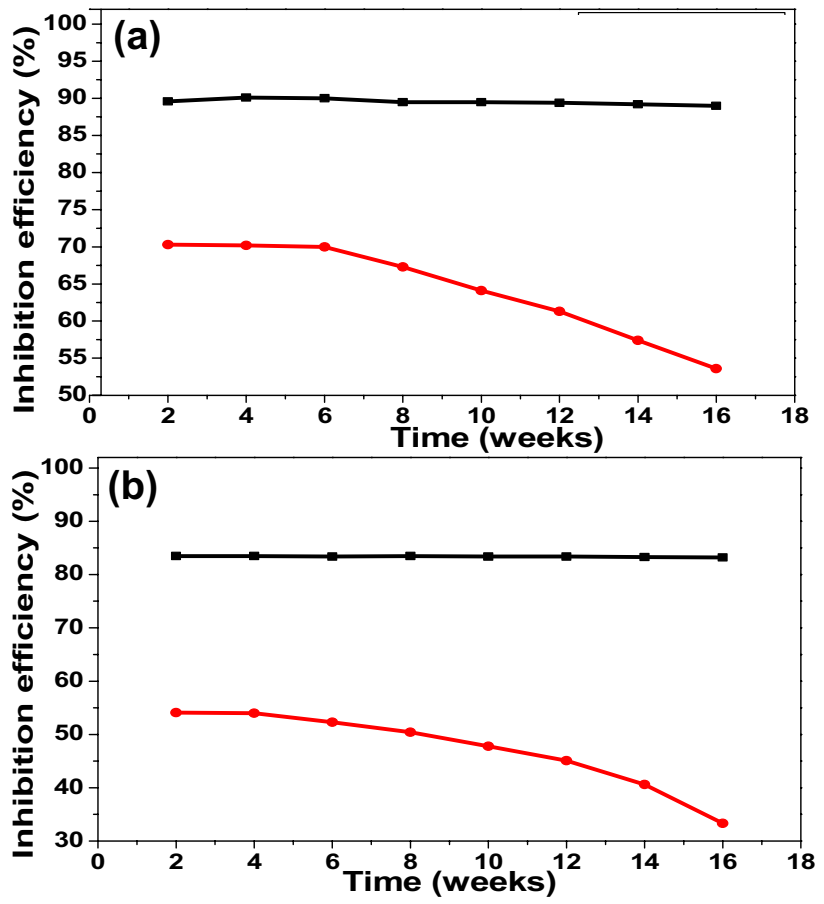

Fig.9 Comparison of inhibition efficiency of $500 \mathrm{mg} / \mathrm{L}$ Et-AgNPs (black line) with $500 \mathrm{mg} / \mathrm{L}$ Et-ACPE (red line) and their stability with preservation time at $\mathbf{a} 30^{\circ} \mathrm{C}$ and $\mathbf{b} 60^{\circ} \mathrm{C}$

interaction between electron rich $-\mathrm{C}=\mathrm{C}$ - groups on the NPs with d-orbitals of $\mathrm{Fe}^{2+}$ on the steel surface, which could be physical in nature.

\subsubsection{EDS}

The elemental composition of the steel surface after immersion for $6 \mathrm{~h}$ in $1 \mathrm{M} \mathrm{HCl}$ containing the Et-AgNPs was elucidated and compared with the surface retrieved from the uninhibited acid solution. The scan was conducted with reference to $\mathrm{C}, \mathrm{N}, \mathrm{O}, \mathrm{Cl}, \mathrm{Ag}$ and Fe atoms only and the obtained EDS profiles are shown in Fig. 10b. It was observed that the steel surface retrieved from the blank acid solution was composed of very high amount of Fe but with no trace of Ag. On addition of Et-AgNPs to the acid, the Fe composition (Wt. \%, Atomic \%) on the surface retrieved from the inhibited solution decreased from $(97.19 \%, 88.53 \%)$ to $(93.58 \%, 83.43 \%)$. This may be due to coverage of Fe sites on the surface by some adsorbed species from the inhibitor such as adsorbed $\mathrm{Ag}(2.45 \%$, $1.13 \%$ ) and other atoms which could have only come from the inhibitor. The amount of $\mathrm{O}$ and $\mathrm{C}$ increased from $(0.16 \%, 0.49 \%)$ and $(2.52 \%, 10.68 \%)$ to $(0.76 \%, 2.28 \%)$ and $(3.11 \%, 12.90 \%)$ respectively. This implies $\mathrm{C}$ and $\mathrm{O}$ from the inhibitor were adsorbed on the surface, thereby covering $\mathrm{Fe}$ atoms. The amounts of $\mathrm{Cl}$ atoms decreased from $(0.11 \%, 0.16 \%)$ to $(0.08 \%, 0.11 \%)$ supporting replacement 

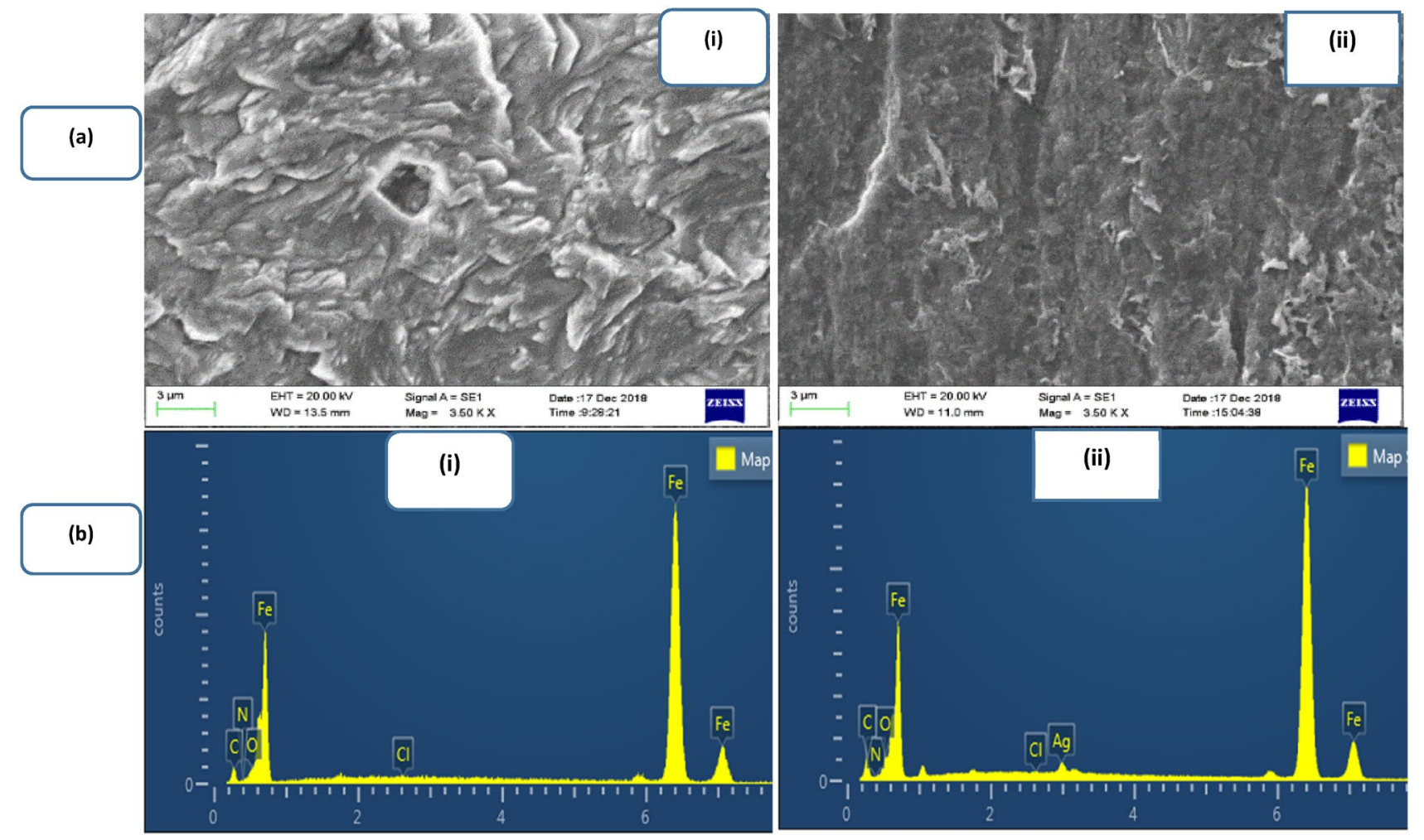

Fig. 10 a SEM micrographs and $\mathbf{b}$ EDS spectra of $\mathrm{X} 80$ steel surface retrieved from (i) $1 \mathrm{M} \mathrm{HCl}$ solution and (ii) $1 \mathrm{M} \mathrm{HCl} \mathrm{solution} \mathrm{inhibited} \mathrm{with}$ $20 \%$ Et-AgNPs

of chloride ions with inhibitor species on the surface. Previous EDS investigation using the NPs revealed it contains no $\mathrm{N}$ atoms. However, EDS analyses of the steel surface reveals that it was composed of $(0.16 \%, 0.49 \%)$ of $\mathrm{N}$ before corrosion inhibition and negligible $\mathrm{N}(0.01 \%, 0.03 \%)$ after inhibition, which removes the possibility of involvement of $\mathrm{N}$ in the adsorption process because the observed $\mathrm{N}$ could have come from air.

\subsection{Morphological examination and surface protection}

\subsubsection{SEM}

X80 steel surfaces retrieved from both uninhibited and inhibited $1 \mathrm{M} \mathrm{HCl}$ were observed by SEM and their morphologies are shown in Fig. 10a. When the inhibitor was not added, corrosive attack resulted in severe damage of the surface, but with inhibitor, the surface was reasonably smooth with only slight corrosive damage. This demonstrates that Et-AgNPs has great potential to suppress the corrosion of X80 steel, although it does not stop the corrosion completely. By comparing the morphologies, it can be affirmed that Et-AgNPs shows excellent retarding effect on the steel corrosion in $1 \mathrm{M} \mathrm{HCl}$ solution even within the $6 \mathrm{~h}$ contact time.

\subsubsection{AFM}

The surface features and morphologies of X80 steel surface immersed in $1 \mathrm{M} \mathrm{HCl}$ without and with Et-AgNPs also were examined at nano- to micro-scale using AFM [5]. We obtained 3D images of the peaks and pits on the surfaces as well as 2D photos of the amplitude and topography surfaces and these are shown in Fig. 11. It was observed that in the blank solution, extreme surface roughness with many pits and peaks were prevalent, indicating severe damage due to rapid corrosion by the acid. Depths of surface pits and heights of peaks were compared from root mean square (RMS) height parameters data generated from the experiment (Fig. 11(iv)). RMS estimation since is considered to be of high sensitivity to large surface deviations with respect to the mean line $[48,49]$. In the absence and presence of EtAgNPs, the maximum peak heights (Sp) were $547 \mathrm{~nm}$ and $200 \mathrm{~nm}$ above the mean plane of the surface, respectively, whereas the deepest pits (Sv) were $444 \mathrm{~nm}$ and $200 \mathrm{~nm}$ below the mean plane of the surface, respectively. These clearly show that deeper pits and higher 
(i)
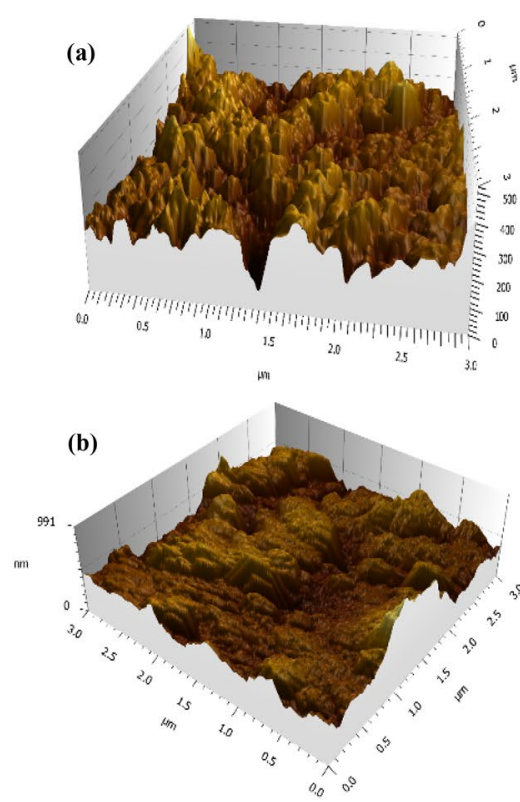

(ii)
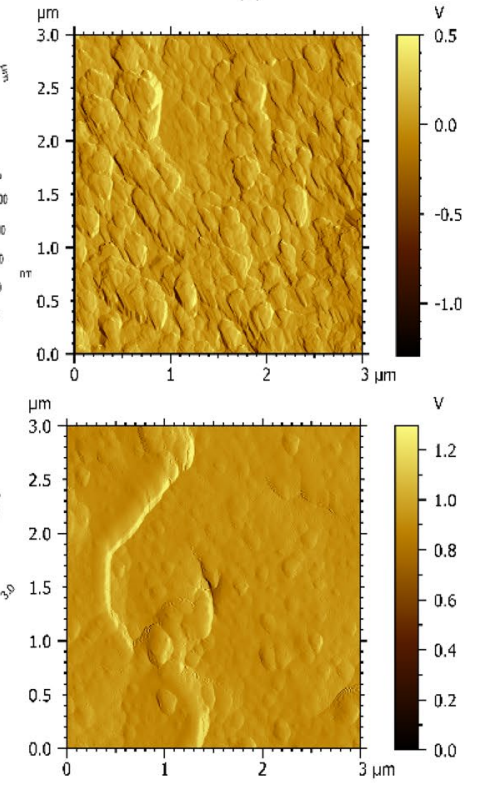

(iii)
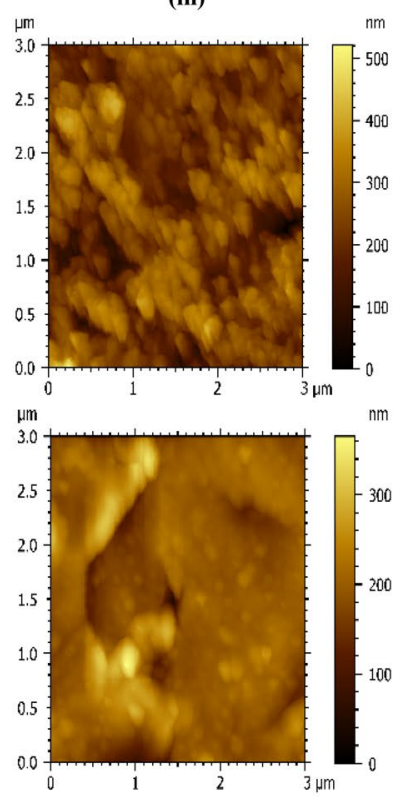

(iv)

\begin{tabular}{|l|r|l|}
\hline \multicolumn{2}{|l|}{ ISO 25178} \\
\hline \multicolumn{3}{|l|}{ Height Parameters } \\
\hline Sq & 101 & $\mathrm{~nm}$ \\
\hline Ssk & 0.313 & \\
\hline Sku & 4.35 & \\
\hline Sp & 547 & $\mathrm{~nm}$ \\
\hline Sv & 444 & $\mathrm{~nm}$ \\
\hline Sz & 991 & $\mathrm{~nm}$ \\
\hline Sa & 78.2 & $\mathrm{~nm}$ \\
\hline
\end{tabular}

\section{ISO 25178}

Height Parameters

\begin{tabular}{|l|r|l|}
\hline Sq & 34.3 & $\mathrm{~nm}$ \\
\hline Ssk & 0.441 & \\
\hline Sku & 5.76 & \\
\hline Sp & 166 & $\mathrm{~nm}$ \\
\hline Sv & 200 & $\mathrm{~nm}$ \\
\hline Sz & 365 & $\mathrm{~nm}$ \\
\hline Sa & 24.0 & $\mathrm{~nm}$ \\
\hline
\end{tabular}

Fig. 11 AFM images of (i) 3D morphology (ii) amplitude (iii) topographyand (iv) height parameters for X80 steel surface after immersion in a $1 \mathrm{M} \mathrm{HCl}$ and $\mathbf{b} 1 \mathrm{M} \mathrm{HCl}$ inhibited by Et-AgNPs

peaks were created by corrosive damage due to the blank acid solution than when Et-AgNPs was added [5, 54]. In comparison with the blank acid, addition of EtAgNPs reduces pitting by about $69.7 \%$ and reduces peak heights by $55.0 \%$, which indicates highly efficient anticorrosion effect.

RMS heights $(S q)$ were $101 \mathrm{~nm}$ and $34.3 \mathrm{~nm}$ without and with Et-AgNPs respectively. The magnitude of $S q$ portrays the standard deviation of peak height at a defined area from the mean plane [29]. Thus, on adding Et-AgNPs, peaks height due to corrosion damage reduced averagely by about $66.0 \%$ in comparison with the blank. Skewness parameter $(S s k<0)$ indicates that height distribution in the presence of inhibitor were more skewed above the mean plane; kurtosis $(S k u>3)$ parameter indicates reduction in spiking of height distribution in the presence of the NPs $[29,54,55]$. Also, the maximum height $(S z)$ and arithmetic mean height $\mathrm{S} \mathrm{Sa}$ ) attained due to corrosive damage of the surface by the acid was $991 \mathrm{~nm}$ and $78.2 \mathrm{~nm}$ respectively, but in the presence of the inhibitor, these heights respectively reduced to $365 \mathrm{~nm}$ and $24.0 \mathrm{~nm}$ corresponding to $63.2 \%$ and $69.3 \%$ reduction, respectively. The results obtained from AFM studies and all the associated RMS parameters confirm that addition of the Et-AgNPs afforded a relatively smoother steel surface with minimal pits and reduced surface degradation, hence efficient corrosion protection.

\subsection{Comparative study}

Many corrosion inhibitors derived from plant materials are not stable - they easily degrade in the presence of heat or when stored for long due to actions of biochemical agents. This places limitation on the application of this kind of corrosion inhibitors. Various plant-based corrosion inhibitors have been reported for similar application as the materials reported in this study. For instance, many of such materials have been documented in a recent review [56]. In comparison, ET-AgNPs competes with or performs better than many of such corrosion inhibitors in terms of efficiency. Some examples include Longan peels extract [57], Musa paradiaca (banana) peels extract [58], rice hull extracts [59], watermelon rind extracts [60], Pisum sativum peels extracts [61] and Rollina occidentalis extract [62]. in addition, Et-AgNPs is also more efficient than nanoparticles composites prepared from olive leaves extract [19] and Musa paradisiaca peels extracts [63]which were recently reported in literature.

\section{Conclusions}

Green silver nanoparticles were synthesized using ethanol extracts of Allim cepa peels and silver nitrate, characterized and evaluated as corrosion inhibitor for $\mathrm{X} 80$ steel in $1 \mathrm{M} \mathrm{HCl}$. Based on our results, it has been concluded that 
Et-AgNPs produces plasmon absorption at $435 \mathrm{~nm}$ and its formation occur within $85 \mathrm{~min}$. Et-AgNPs are crystalline with no defects, having a fcc structure with Ag atoms predominantly oriented along (111) plane. Et-AgNPs synthesized are non-aggregating, monodispersed with spherical shapes and particle sizes distributed between the range of 20-50 nm. Et-AgNPs surface contains more O sites which conveys higher adsorptive capacity than the crude extract. The NPs are $89.7 \%$ and $83.5 \%$ efficient in inhibiting corrosion of $X 80$ steel in $1 \mathrm{M} \mathrm{HCl}$ at $30^{\circ} \mathrm{C}$ and $60^{\circ} \mathrm{C}$, respectively, and act as mixed type inhibitor with dominant effect on anodic half reaction. Addition of the NPs reduces pits and peaks due to acid corrosive attack by $69.7 \%$ and $66.0 \%$ respectively, protects steel surface against corrosion. Interaction of the NPs with steel surface results in formation of surface complex facilitated by $\mathrm{O}$ sites in the NPs. Et-AgNPs from ACPE is suitable for application as green, inexpensive and efficient alternative corrosion inhibitor for oilfield pickling and cleaning operations.

Acknowledgements Authors are thankful to the financial assistance provided by the National Natural Science Foundation of China (No. 52074232). Also, the authors appreciate the assistance of Ruiyun $\mathrm{Li}$ and Ubong Etim during the conduct of the experiments and data analyses.

\section{Declarations}

Conflict of interest We declare that there is no conflict of interest among authors.

Open Access This article is licensed under a Creative Commons Attribution 4.0 International License, which permits use, sharing, adaptation, distribution and reproduction in any medium or format, as long as you give appropriate credit to the original author(s) and the source, provide a link to the Creative Commons licence, and indicate if changes were made. The images or other third party material in this article are included in the article's Creative Commons licence, unless indicated otherwise in a credit line to the material. If material is not included in the article's Creative Commons licence and your intended use is not permitted by statutory regulation or exceeds the permitted use, you will need to obtain permission directly from the copyright holder. To view a copy of this licence, visit http://creativecommons. org/licenses/by/4.0/.

\section{References}

1. Mishra A, Shoesmith D, Manning P (2016) Materials selection for use in concentrated hydrochloric acid. Corros 73:68

2. Goyal M, Kumar S, Bahadur I, Verma C, Ebenso EE (2018) Organic corrosion inhibitors for industrial cleaning of ferrous and nonferrous metals in acidic solutions: a review. J Mol Liq 256:565

3. Finšgar M, Jackson J (2014) Application of corrosion inhibitors for steels in acidic media for the oil and gas industry: a review. Corros Sci 86:17

4. Rani BE, Basu BBJ (2012) Green inhibitors for corrosion protection of metals and alloys: an overview. Int J Corros. https://doi. org/10.1155/2012/380217
5. Ituen E, Singh A, Yuanhua L, Li R (2020) Synthesis and evaluation of anticorrosion properties of onion mesocarp-nickel nanocomposites on X80 steel in acidic cleaning solution. J Mater Res Technol. https://doi.org/10.1016/j.jmrt.2020.01.017

6. Eduok UM, Umoren SA, Udoh AP (2012) Synergistic inhibition effects between leaves and stem extracts of Sida acuta and iodide ion for mild steel corrosion in $1 \mathrm{M} \mathrm{H}_{2} \mathrm{SO}_{4}$ solutions. Arabian J Chem 5:325

7. Krishnaveni K, Ravichandran J (2014) Effect of aqueous extract of leaves of Morinda tinctoria on corrosion inhibition of aluminium surface in $\mathrm{HCl}$ medium. Transac Nonferr Metals Soc China 24:2704

8. Jokar M, Farahani TS, Ramezanzadeh B (2016) Electrochemical and surface characterizations of morus alba pendula leaves extract (MAPLE) as a green corrosion inhibitor for steel in $1 \mathrm{M}$ $\mathrm{HCl}$. J Taiwan Inst Chem Eng 63:436

9. Abrishami S, Naderi R, Ramezanzadeh B (2018) Fabrication and characterization of zinc acetylacetonate/Urtica Dioica leaves extract complex as an effective organic/inorganic hybrid corrosion inhibitive pigment for mild steel protection in chloride solution. Appl Surf Sci 457:487

10. Ramezanzadeh M, Sanaei Z, Bahlakeh G, Ramezanzadeh B (2018) Highly effective inhibition of mild steel corrosion in $3.5 \% \mathrm{NaCl}$ solution by green Nettle leaves extract and synergistic effect of eco-friendly cerium nitrate additive: Experimental, MD simulation and QM investigations. J Mol Liq 25:67

11. Loto RT (2018) Surface coverage and corrosion inhibition effect of Rosmarinus officinalis and zinc oxide on the electrochemical performance of low carbon steel in dilute acid solutions. Res Phys 8:172

12. Bahlakeh G, Ramezanzadeh M, Ramezanzadeh B (2017) Experimental and theoretical studies of the synergistic inhibition effects between the plant leaves extract (PLE) and zinc salt (ZS) in corrosion control of carbon steel in chloride solution. J Mol Liq 248:854

13. Sanaei Z, Shahrabi T, Ramezanzadeh B (2017) Synthesis and characterization of an effective green corrosion inhibitive hybrid pigment based on zinc acetate-Cichorium intybus $L$ leaves extract ( $\mathrm{ZnA}-\mathrm{CIL}$. L): Electrochemical investigations on the synergistic corrosion inhibition of mild steel in aqueous chloride solutions. Dyes Pigm 139:218

14. Loto RT, Olowoyo O (2018) Corrosion inhibition properties of the combined admixture of essential oil extracts on mild steel in the presence of $\mathrm{SO}_{4}{ }^{2-}$ anions. South African J Chem Eng 26:35

15. Motamedi M, Ramezanzadeh B, Mahdavian M (2018) Corrosion inhibition properties of a green hybrid pigment based on $\mathrm{Pr}$ Urtica Dioica plant extract. J Indus Eng Chem 66:116

16. Mittal AK, Chisti Y, Banerjee UC (2013) Synthesis of metallic nanoparticles using plant extracts. Biotechnol Adv 31:346

17. Ahmed S, Ahmad M, Swami BL, Ikram S (2016) A review on plants extract mediated synthesis of silver nanoparticles for antimicrobial applications: a green expertise. J Adv Res 7:17

18. Ituen E, Ekemini E, Yuanhua L, Li R, Singh A (2020) Mitigation of microbial biodeterioration and acid corrosion of pipework steel using Citrus reticulata peels extract mediated copper nanoparticles composite. Int Biodeterior Biodegrad 149:104935

19. Essien EA, Kavaz D, Ituen EB, Umoren SA (2018) Synthesis, characterization and anticorrosion property of olive leaves extracttitanium nanoparticles composite. J Adhes Sci Technol 32:1773

20. Idrees M, Batool S, Kalsoom T, Raina S, Sharif HMA, Yasmeen S (2019) Biosynthesis of silver nanoparticles using Sida acuta extract for antimicrobial actions and corrosion inhibition potential. Environ Technol 40:1071

21. Ituen $E$, Singh $A$, Yuanhua $L$ (2020) Inhibitive effect of onion mesocarp extract-nickel nanoparticles composite on simultaneous 
hydrogen production and pipework corrosion in $1 \mathrm{M} \mathrm{HCl}$. Int J Hydro Energy 45:10814

22. Ituen E, Ekemini E, Yuanhua L, Singh A (2020) Green synthesis of Citrus reticulata peels extract silver nanoparticles and characterization of structural, biocide and anticorrosion properties. J Mol Struct 1207:127819

23. Kwak JH, Seo JM, Kim NH, Arasu MV, Kim S, Yoon MK, Kim SJ (2017) Variation of quercetin glycoside derivatives in three onion (Allium cepa L.) varieties. Saudi J Biol Sci 24:1387

24. Gennaro L, Leonardi C, Esposito F, Salucci M, Maiani G, Quaglia G, Fogliano V (2002) Flavonoid and carbohydrate contents in Tropea red onions: effects of homelike peeling and storage. J Agric Food Chem 50:1904

25. Khadom AA, Abd AN, Ahmed NA (2018) Xanthium strumarium leaves extracts as a friendly corrosion inhibitor of low carbon steel in hydrochloric acid: Kinetics and mathematical studies. South African J Chem Eng 25:13

26. James AO, Akaranta $\mathrm{O}$ (2009) Corrosion inhibition of aluminum in $2.0 \mathrm{M}$ hydrochloric acid solution by the acetone extract of red onion skin. African J Pure Appl Chem 3:262

27. Ong CC, Karim KA (2017) Inhibitory effect of red onion skin extract on the corrosion of mild steel in acidic medium. Chem Eng Transac 56:913

28. Iroha NB, Akaranta O, James AO (2012) Red onion skin extractfurfural resin as corrosion inhibitor for aluminium in acid medium. Der Chem Sinica 3:995

29. Singh A, Ituen EB, Ansari KR, Chauhan DS, Quraishi MA (2019) Surface protection of $X 80$ steel using Epimedium extract and its iodide-modified composites in simulated acid wash solution: a greener approach towards corrosion inhibition. New J Chem 43:8527

30. Huang J, Li Q, Sun D, Lu Y, Su Y, Yang X, Wang H, Wang Y, Shao W, He N, Hong J (2007) Biosynthesis of silver and gold nanoparticles by novel sundried Cinnamomum camphora leaf. Nanotechnology 18:105104

31. Rajakumar G, Rahuman AA (2011) Larvicidal activity of synthesized silver nanoparticles using Eclipta prostrata leaf extract against filariasis and malaria vectors. Acta Trop 118:196

32. Sukirtha R, Priyanka KM, Antony JJ, Kamalakkannan S, Thangam R, Gunasekaran P, Krishnamn M, Achiraman S (2012) Cytotoxic effect of Green synthesized silver nanoparticles using Melia azedarach against in vitro HeLa cell lines and lymphoma mice model. Proc Biochem 47:273

33. Saxena A, Tripathi RM, Zafar F, Singh P (2012) Green synthesis of silver nanoparticles using aqueous solution of Ficus benghalensis leaf extract and characterization of their antibacterial activity. Mater Let 67:91

34. Nabikhan A, Kandasamy K, Raj A, Alikunhi NM (2010) Synthesis of antimicrobial silver nanoparticles by callus and leaf extracts from saltmarsh plant, Sesuvium portulacastrum L. Colloids Surf B Biointerf 79:488

35. Prabu HJ, Johnson I (2015) Plant-mediated biosynthesis and characterization of silver nanoparticles by leaf extracts of Tragia involucrata, Cymbopogon citronella, Solanum verbascifolium and Tylophora ovata. Karbala Int J Modern Sci 1:237

36. Karthiga P (2018) Preparation of silver nanoparticles by Garcinia mangostana stem extract and investigation of the antimicrobial properties. Biotechnol Res Innov 2:30

37. Sur UK, Ankamwar B, Karmakar S, Halder A, Das P (2018) Green synthesis of Silver nanoparticles using the plant extract of Shikakai and Reetha. Mater Today Proceed 5:2321

38. Behravan M, Panahi AH, Naghizadeh A, Ziaee M, Mahdavi R, Mirzapour A (2019) Facile green synthesis of silver nanoparticles using Berberis vulgaris leaf and root aqueous extract and its antibacterial activity. Int J Biol Macromol 124:148
39. Gul S, Ismail M, Khan MI, Khan SB, Asiri AM, Rahman IU, Khan MA, Kamboh MA (2016) Novel synthesis of silver nanoparticles using melon aqueous extract and evaluation of their feeding deterrent activity against housefly Musca domestica. Asian Pac J Trop Dis 6:311

40. Banala RR, Nagati VB, Karnati PR (2015) Green synthesis and characterization of Carica papaya leaf extract coated silver nanoparticles through X-ray diffraction, electron microscopy and evaluation of bactericidal properties. Saudi J Biol Sci 22:637

41. Saber H, Alwaleed EA, Ebnalwaled KA, Sayed A, Salem W (2017) Efficacy of silver nanoparticles mediated by Jania rubens and Sargassum dentifolium macroalgae; Characterization and biomedical applications. Egyp J Basic Appl Sci 4:249

42. Vijayakumar S (2019) Eco-friendly synthesis of gold nanoparticles using fruit extracts and in vitro anticancer studies. J Saudi Chem Soc 23:753

43. Xu X, Singh A, Sun Z, Ansari KR, Lin Y (2017) Theoretical, thermodynamic and electrochemical analysis of biotin drug as an impending corrosion inhibitor for mild steel in 15\% hydrochloric acid. RSC Open Sci 4:170933

44. Nayak D, Ashe S, Rauta PR, Kumari M, Nayak B (2016) Bark extract mediated green synthesis of silver nanoparticles: evaluation of antimicrobial activity and antiproliferative response against osteosarcoma. Mater Sci Eng C 58:44

45. Ituen E, Mkpenie V, Ekemini E (2019) Corrosion inhibition of X80 steel in simulated acid wash solution using glutathione and its blends: experimental and theoretical studies. Colloid Surf A Physicochem Eng Asp 578:123597

46. Pontaza-Li' cona YS, Ramos-Jacques AL, Cervantes-Chavez JA, López-Miranda JL, de Jesús R-B Á, Maya-Cornejo J, HernandezMartínez AR (2019) Alcoholic extracts from Paulownia tomentosa leaves for silver nanoparticles synthesis. Res Phys 12:1670

47. Ituen E, Mkpenie V, Moses E, Obot I (2019) Electrochemical kinetics, molecular dynamics, adsorption and anticorrosion behavior of melatonin biomolecule on steel surface in acidic medium. Bioelectrochem 129:42

48. Umoren SA, Ogbobe O, Okafor PC, Ebenso EE (2017) Polyethylene glycol and polyvinyl alcohol as corrosion inhibitors for aluminium in acidic medium. J Appl Polym Sci 105:3363

49. Dohare P, Quraishi MA, Obot IB (2018) A combined electrochemical and theoretical study of pyridine-based Schiff bases as novel corrosion inhibitors for mild steel in hydrochloric acid medium. J Chem Sci 130:8

50. Ituen E, Mkpenie V, Yuanhua L, Singh A (2020) Inhibition of erosion corrosion of pipework steel in descaling solution using 5-hydroxytryptamine-based additives: empirical and computational studies. J Mol Struct 1204:127562

51. Gao H, Xie N, Zhang J, Sun J, Zhang J, Jin Z (2020) Synthesis and application of carboxyethylthiosuccinic acid by thiol-ene click reaction: as a novel rust remover with corrosion inhibition properties. J Chem Sci 132:1

52. Mobin M, Basik M, Shoeb M (2019) A novel organic-inorganic hybrid complex based on Cissus quadrangularis plant extract and zirconium acetate as a green inhibitor for mild steel in $1 \mathrm{M}$ $\mathrm{HCl}$ solution. Appl Surf Sci 469:38

53. Ituen EB, James AO, Akaranta O (2017) Fluvoxamine-based corrosion inhibitors for $\mathrm{J} 55$ steel in aggressive oil and gas well treatment fluids. Egypt J Petrol 26:745

54. Benardos PG, Vosniakos GC (2003) Predicting surface roughness in machining: a review. Int J Mach Tools Manufac 43:833

55. Sahin Y, Motorcu AR (2005) Surface roughness model for machining mild steel with coated carbide tool. Mater Design 26:321

56. Umoren SA, Solomon MM, Obot IB, Suleiman RK (2019) A critical review on the recent studies on plant biomaterials as corrosion inhibitors for industrial metals. J Ind Eng Chem 76:91 
57. Liao LL, Mo S, Luo HQ, Li NB (2017) Longan seed and peel as environmentally friendly corrosion inhibitor for mild steel in acid solution: experimental and theoretical studies. J Colloid Interf Sci 499:110

58. Ji G, Anjum S, Sundaram S, Prakash R (2015) Musa paradisica peel extract as green corrosion inhibitor for mild steel in $\mathrm{HCl}$ solution. Corros Sci 90:107

59. Prabakaran M, Kim SH, Oh YT, Raj V, Chung IM (2017) Anticorrosion properties of momilactone $A$ isolated from rice hulls. J Ind Eng Chem 45:380

60. Odewunmi NA, Umoren SA, Gasem ZM (2015) Watermelon waste products as green corrosion inhibitors for mild steel in $\mathrm{HCl}$ solution. J Environ Chem Eng 3:286

61. Srivastava M, Tiwari P, Srivastava SK, Kumar A, Ji G, Prakash R (2018) Low cost aqueous extract of Pisum sativum peels for inhibition of mild steel corrosion. J Mol Liq 254:357
62. Alvarez APE, Fiori-bimbi MV, Neske A, Brand SA, Gervasi CA, Brand SA (2018) Rollinia occidentalis extract as green corrosion inhibitor for carbon steel in $\mathrm{HCl}$ solution. J Ind Eng Chem 58:92

63. Ituen E, Mkpenie V, Ekemini E (2019) Adsorptive Fe-nanoparticles mediated by Musa sapientum peels extract as anticorrosion additive for aqueous oilfield descaling solution. Scientif Afr 3:e00075

Publisher's Note Springer Nature remains neutral with regard to jurisdictional claims in published maps and institutional affiliations. 